\title{
Postinjury Niches Induce Temporal Shifts in Progenitor Fates to Direct Lesion Repair after Spinal Cord Injury
}

\author{
Drew L. Sellers, ${ }^{1}$ Don 0. Maris, ${ }^{1}$ and Philip J. Horner ${ }^{1,2}$ \\ ${ }^{1}$ Department of Neurological Surgery, University of Washington, Seattle, Washington 98104, and ${ }^{2}$ Neurobiology and Behavior Program, University of \\ Washington, Seattle, Washington 98015
}

Progenitors that express NG2-proteoglycan are the predominant self-renewing cells within the CNS. NG2 progenitors replenish oligodendrocyte populations within the intact stem cell niche, and cycling NG2 cells are among the first cells to react to CNS insults. We investigated the role of NG2 progenitors after spinal cord injury and how bone morphogen protein signals remodel the progressive postinjury (PI) niche. Progeny labeled by an NG2-specific reporter virus undergo a coordinated shift in differentiation profile. NG2 progeny born $24 \mathrm{~h}$ PI produce scar-forming astrocytes and transient populations of novel phagocytic astrocytes shown to contain denatured myelin within cathepsin-D-labeled endosomes, but NG2 progenitors born $7 \mathrm{~d}$ PI differentiate into oligodendrocytes and express myelin on processes that wrap axons. Analysis of spinal cord mRNA shows a temporal shift in the niche transcriptome of ligands that affect PI remodeling and direct progenitor differentiation. We conclude that NG2 progeny are diverse lineages that obey progressive cues after trauma to replenish the injured niche.

\section{Introduction}

The microenvironments that regulate stem cells/progenitors serve to maintain homeostasis in adult tissue. The support cells and molecular cues within these microenvironments comprise the niches that instruct progenitors within the CNS (Jordan et al., 2007; Ninkovic and Götz, 2007). Although the importance of niches has been realized, little information has been presented to describe how injuries feedback and stimulate progenitors, or how cellular deficits are replenished within the damaged nervous system to facilitate niche succession (Fuchs et al., 2004).

Despite limited posttraumatic regeneration, the spinal cord is known to contain endogenous neural progenitor cells (NPCs) that support plasticity in the mammalian CNS (Weiss et al., 1996; Johansson et al., 1999; Namiki and Tator, 1999; Horner et al., 2000; Shihabuddin et al., 2000). Stem cell niches have been characterized for several CNS regions (Doetsch et al., 1999; Palmer, 2002; Kempermann et al., 2004). Within these regions, niche succession is characterized by asymmetric cell division of stem cells to produce one stem cell and one daughter cell. The daughter cell progresses to differentiate terminally and replenish tissue requirements as directed by the intact niche (Alvarez-Buylla and Lim, 2004). Pigment epilethium (Ramirez-Castillejo et al., 2006) promotes self-renewal, whereas sonic hedgehog (Shh) (Ahn and Joyner, 2004) and bone morphogen protein (BMP) (Lim et al.,

\footnotetext{
Received Sept. 22, 2008; revised Feb. 20, 2009; accepted April 13, 2009.

This work was supported by grants from the National Institutes of Health (NSO46724) and the Paralyzed Veterans of America.

Correspondence should be addressed to either Drew L. Sellers or Philip J. Horner, Department of Neurological Surgery, 325 9th Avenue, Box 359655, Seattle, WA 98104, E-mail: drewfus@u.washington.edu or phorner@u.washington.edu.

DOI:10.1523/JNEUROSCI.4538-08.2009

Copyright $\odot 2009$ Society for Neuroscience $\quad$ 0270-6474/09/296722-12\$15.00/0
}

2000) signals maintain stemness as molecular cues evolve within the neural stem cell (NSC) niche to direct differentiation within neurogenic versus gliogenic regions (H. Song et al., 2002; H. J. Song et al., 2002; Shen et al., 2004). Thus, the NSC niche is a refined microenvironment evolved to facilitate communication between tissues and stem cells to sustain homeostasis. Analogous processes occur in hematopoesis, hair follicle, and germ cell niches. Yet, a stem cell niche has not been defined within the spinal cord, despite the observation of proliferative zones (Johansson et al., 1999; Horner et al., 2000).

Spinal cord injury (SCI) produces a structural perturbation to the homeostasis of a NSC niche known to stimulate the proliferation of reactive cells and produce an inhibitory scar that restricts regeneration (Silver and Miller, 2004). Numerous studies have examined how injuries to the brain or spinal cord affect NSCs and how NSCs respond to growth factors injected into the CNS after injury. Although informative, intervention studies fail to examine how the niche evolves postinjury (PI) to rebuild damaged tissue: the process of PI niche succession. To investigate how a progressive niche recovers after injury, we targeted CNS progenitors marked by NG2-proteoglycan expression. Cycling cells that express NG2 are the most abundant progenitor in the rodent CNS (Horner et al., 2002; Dawson et al., 2003), and NG2 cells are known to respond to injury and are thought to be restricted oligodendrocyte precursor cells (OPCs) (Levine and Reynolds, 1999). However, a clear impediment to conducting lineage studies within the injured niche is the dramatic deposition of proteoglycans throughout the injury zone making the determination of the cellular source and the phenotypic fate of NG2-expressing cells equivocal. Therefore, we engineered a retroviral reporter virus to specifically target NG2-expressing cells to determine how traumatized microenvironments feedback to instruct progenitors after injury. 


\section{Materials and Methods}

SCI (hemisection) and tissue processing. Adult mice ( 8 weeks) were anesthetized with avertin (12.6\% tribromo-ethanal, $0.6 \%$ tert-amyl alcohol; Sigma) to perform a T9-T10 laminectomy. After exposure of the dorsal cord, iridectomy scissors were used to create a hemisection lesion by cutting the dorsal spinal cord tissue until the central canal could be visualized ( $\sim 300 \mu \mathrm{m}$ deep). After a successful lesion, the muscle and skin were sutured in layers to close the wound. Postoperatively, lactated Ringer's solution was administered subcutaneously to rehydrate the animals. Analgesics ( $0.05 \mathrm{mg} / \mathrm{kg}$ buprenorphine) and antibiotics ( $4.8 \mu \mathrm{g} / \mathrm{g}$ gentamicin; Abraxis Pharmaceutical Products) were administered as needed, and animals recovered from surgery in warmed cages.

To harvest spinal cords, anesthetized mice were killed via intracardiac perfusion. Animals were exsanguinated with saline and fixed with $4 \%$ paraformaldehyde (containing 4\% sucrose). Perfused tissue was equilibrated in 30\% sucrose for cryoprotection in OTC medium and serially sectioned (1:6, $20 \mu \mathrm{m}$ coronal/cross sections) with a Leica SM1850 cryostat.

For BMP ligand injection and progenitor transplantation, similar methods were followed. Each study was coded and blinded. BMP4 and noggin (carrier free; R \& D Systems) were administered by intraspinal injection $(1 \mu \mathrm{l}$ of $50 \mu \mathrm{g} / \mathrm{ml}$ stock, within $1 \mathrm{~mm}$ rostral to the lesion, respectively). After amplification, 26 Sor $^{\star}$ cells were harvested with custom ATV and resuspended in HBSS $\left(1 \times 10^{8} \mathrm{cells} / \mathrm{ml}\right)$. Cells were transplanted by injection, $1 \mathrm{~mm}$ rostral to the hemisection lesion, with a pulled glass micropipette into the spinal cord (1-2 $\mu$ l injection administered over the course of 2 min with a 2 min dwell time after completion: 4 min total). Glass micropipettes minimize injuries incurred by Hamilton syringes.

NG2 promoter cloning (gene walking) and validation. Murine genomic DNA was purified from adult NPCs lysed with Trizol (Invitrogen). To clone the DNA sequence that regulates NG2 expression, a targeted antisense PCR primer was designed to target a region encoding the NG2 protein, $\sim 80$ bp downstream of the ATG start site. The targeted primer was used in conjunction with random primers to amplify segments of genomic DNA that could regulate NG2 expression. The products isolated from the primary reaction were used as templates for a second PCR. In the secondary reaction, a nested primer, directed against the $5^{\prime}$ untranslated region of NG2, was used to confirm which isolates are derived from the regions upstream of NG2. Positive isolates are cloned and confirmed by DNA sequencing. Each sequence is BLAST searched (National Center for Biotechnology Information BLAST), and subsequent primers are designed to target and isolate 1584 bp upstream of the NG2 translational start site (5'-GGAGGGGAAAGTCAAAGGTTCACAGAAGACCCTC3'; Operon Biotechnologies).

After sequence confirmation and analysis, a series of NG2 promoter truncations (nine total; $3^{\prime}$ and $5^{\prime}$ mutants) evaluated promoter activity and isolated the regions required to regulate transcription stringently. Each truncation created by PCR mutagenesis was subcloned into pGL3basic (promoterless mammalian expression vector; Promega) to regulate luciferase expression. Thus, pGL3 vectors report promoter activity according to luciferase activity. Consequently, COS and PC12 cells (American Type Culture Collection) transfected with the recombinant promoter plasmid quantified transcriptional activation as a function of the luminescence produced by luciferase activity, in cell lysates. Using bright-lite (PerkinElmer Life and Analytical Sciences) as the substrate, luminescence was measured (in a 96-well plate; NUNC) using a Packard Fusion plate analyzer (PerkinElmer Life and Analytical Sciences) and normalized against control (promoterless) to evaluate NG2 promoter activity.

NG2-reporter Maloney virus construct and production. A mouse Maloney retrovirus, constructed to express green fluorescent protein (GFP), tracked the proliferation and differentiation of NG2-expressing progenitors. Within the confirmed NG2 promoter sequence in a TOPO-PCR2.1 plasmid (Invitrogen), PCR mutagenesis inserted an NcoI endoneclease site at the NG2 ATG start site, and the product was cloned into pBR322 (New England Biolabs). The mutant NcoI site permitted enhanced GFP (EGFP) to be inserted into the translational start site regulated by the
NG2 promoter. DNA sequencing confirmed the reading frame and placement of the chimeric EGFP reporter (NG2pEGFP), with respect to the NG2 promoter. After confirmation, a standard T4 Ligase (New England Biolabs) reaction inserted the excised NG2pEGFP expression cassette (EcoRI and EcoRV digest from pBR322; the full-length 1580 bp NG2 promoter with EGFP) into the pLAPSN retroviral vector (EcoRI and HpaI sites; Invitrogen). Positive colonies that harbor the recombinant plasmid were selected from ampicillin (Sigma) agar plates $(50 \mu \mathrm{g} / \mathrm{ml})$, and the plasmid was amplified and isolated according to standard recombinant DNA techniques. Within pLAPSN, NG2pEGFP was inserted 3' of the long terminal repeat (LTR) and in reverse orientation of the alkaline phosphatase (AP) gene. Therefore, the recombinant vector is designated $\mathrm{pL}_{\mathrm{r}} \mathrm{NpEAPSN}$. Similar methods were used to produce a cre-recombinase expression vector: $\mathrm{pLNpCRESN}$.

Phoenix-GP packaging cells (American Type Culture Collection) were used to package and produce recombinant viral particles. Briefly, $\mathrm{pL}_{\mathrm{r}} \mathrm{N}$ pEAPSN was cotransfected with the VSVG envelope vector into Phoenix-GP cells. In DMEM (Invitrogen), Fugene 6 (Roche) was mixed at a 3:1 ration with the vector constructs (1 $\mu \mathrm{g}$ each). The transfection mixture was added to cells ( $60 \%$ confluent) with gentle shaking in $4.5 \mathrm{ml}$ of serum-free medium (10 cm dish) supplemented with $1 \mu \mathrm{g} / \mathrm{ml}$ Polybrene (Sigma). After $18-24 \mathrm{~h}$, cell medium was supplemented with serum (10\%), hygromycin (0.3 mg/ml; Invitrogen), and G418 (30 $\mu \mathrm{g} / \mathrm{ml}$; Omega Scientific). Infectious virus particles harvested from the medium are concentrated to $1 \times 10^{9}$ infectious particles per microliter (high titer) via ultracentrifugation (Beckman Ultracentrifuge; $24,000 \times g, 70.1 \mathrm{Ti}$ rotor at $4^{\circ} \mathrm{C}$ for $2 \mathrm{~h}$ )

In vivo experiments required high-titer virus for injection $(1 \mu \mathrm{l}), 1 \mathrm{~mm}$ rostral to the lesion, into the dorsal columns of adult mice, at $24 \mathrm{~h}$ PI or $7 \mathrm{~d}$ PI. Seven and three days after each injection, spinal cord tissue was harvested from perfusion-fixed mice for subsequent analysis (see above). To evaluate the stringency of EGFP expression from the viral genome, and other molecular phenotypes, confocal microscopy quantified and characterized the coincidence of EGFP with phenotypic markers and NG2-proteoglycan in immunologically stained tissue (detailed below). Spinal cord tissue was embedded in OTC medium and frozen to be cryosectioned. Coronal spinal cord sections were mounted on Permafrost slides (Thermo Fisher Scientific) and stored at $-80^{\circ} \mathrm{C}$ for future use.

In vitro infection of isolate cells used high-titer virus diluted into culture in growth medium $\left(\sim 10,000\right.$ cells per $10^{6}$ particles $)$ with $>80 \%$ efficiency. Viral was insured by antibiotic selection with G418 (50 $\mu \mathrm{g} / \mathrm{ml}$, a dose known to kill untransfected NPCs). Infection and recombination was monitored fluorescently and via reverse transcription (RT)-PCR. Cells were purified by EGFP expression, driven by CRE infection, by fluorescence-activated cell sorting (FACS; described below).

Immunofluorescence. Molecular marker expression was evaluated by immunofluorescence to determine the cellular phenotype of virally labeled (EGFP) cells in SCI tissue. Primary antibodies previously shown to identify reactive astrocytes [glial fibrillary acidic protein (GFAP)], immature and mature astrocytes (s100 polypeptide), immature oligodendrocytes [adenomatosis polyposis coli (APC) tumor suppresser gene, CC1 clone], and EGFP are combined to elucidate cell phenotype. It is important to note the $\mathrm{CC} 1$ clone antibody is directed against the $\mathrm{N}$ terminus of APC and is specific for glial cells (Calbiochem), but CC1 does not crossreact with neurons, as reported with antibodies directed against the $\mathrm{C}$ terminus of APC. Combined in blocking buffer (TBS plus $0.3 \%$ Triton plus $5 \%$ donkey serum), three compatible primary antibodies were applied to tissue and incubated overnight at $4^{\circ} \mathrm{C}$. The optimum antibody concentration had been determined by a dilution series: guinea pig $\alpha$-GFAP (1:2500; Advanced Immunochemical), rabbit $\alpha$-s100 $\beta$ (1:5000; Swant), or mouse $\alpha$-s100 $\beta$ (1:1000, clone SB6; Abcam), mouse $\alpha$-CathD (1:200; Millipore Bioscience Research Reagents), rabbit $\alpha$-Caspase 3 (Casp3; cleaved Casp3; Cell Signaling Technologies), mouse $\alpha$-APC (1: 500; Calbiochem), rabbit $\alpha$-NG2 (1:500; Millipore Bioscience Research Reagents), and chicken or rabbit $\alpha$-EGFP (1:2500 or 1:500, respectively; Millipore Bioscience Research Reagents). Chondroitin sulfate proteoglycan (CSPG) was detected by a monoclonal anti-CSPG (clone CS-56; Sigma), and mouse IgG was added to the primary block to reduce nonspecific binding. After the primary incubation, sections were rinsed twice 
Table 1. Real-time PCR primer sets and amplicon size

\begin{tabular}{llll}
\hline Gene & 5' primer sequence & 3' primer sequence & Base pairs \\
\hline noggin & cagccggcggccagcactat & ctctgggggcgaagtggcca & 185 \\
BMP4 & gcttgagtacccggagcgt & tgctgctgaggttgaagagga & 131 \\
0lig1 & gaacgcggctcccgcgacca & gagcggagcttcggccttct & 178 \\
0lig2 & cagagctgagctccgagcta & cgggctcagtcatctgcttctt & 168 \\
PDGF $\alpha$ & ggctgcggatacctcgccca & gcatcctcagccctacgga & 143 \\
NkX2.2 & gaagacggctcggtggccga & gaggccctcggtgctggcca & 180 \\
BMP2 & ccggccttcggaagacgtcct & gcggctggctgcctctcca & 187 \\
GAPDH & cgggaagcccatcaccatct & gggcggagatgatgacccgt & 161 \\
Id1 & cctagctgttcgctgaaggc & gtagagcaggacgttcacct & 141 \\
Id2 & gtccggtgaggtccgttag & tgtagagcagactcatcgggt & 99 \\
Id3 & cgaccgaggagcctcttag & gcaggatttccacctggcta & 114 \\
Shh & tcacaagaaactccgaacgattt & gatgtccactgctcgaccc & 248 \\
\hline
\end{tabular}

in $0.1 \mathrm{M}$ TBS, pH 7.5, and once in blocking buffer. Secondary antibodies were applied in blocking buffer for $2 \mathrm{~h}$ at room temperature, or overnight at $4^{\circ} \mathrm{C}$ : donkey $\alpha$-mouse IgG conjugated to CY3 (1:250; Jackson ImmunoResearch), $\alpha$-rabbit IgG conjugated to CY2 (1:250; Jackson ImmunoResearch), donkey $\alpha$-guinea pig conjugated to CY5 (1:250; Jackson ImmunoResearch), and donkey $\alpha$-chicken Alexa-488 (Invitrogen). Unbound antibody was removed by extensive washes with blocking buffer. All immunostains were verified by a "no primary" secondary antibody stain.

Cell and molecular phenotype quantification. Images of multiple-label immunofluorescence are collected and quantified using confocal microscopy (Bio-Rad Radiance; Carl Zeiss). Confocal $z$-stack images permit optically sectioned stains to be examined to determine which phenotypic markers (outlined above) colocalize with EGFP. The dorsal half of SCI tissue was sampled randomly to quantify the phenotypes of virally labeled cells. Antigen colocalization with EGFP was quantified in serial tissue sections, one-in-six series ( $2 \mathrm{~mm}$ rostral of the dorsal hemisection), from four or five animals per time point. Phenotypes were designated in accordance with antigen (detailed above) colocalization with the well defined cytoplasm of an EGFP-labeled cell, followed through the $z$-axis. A minimum of 100 EGFP cells was examined from 12 to 16 sections.

Quantitative real-time PCR. Tissue sections (1-2 $\mathrm{mm})$ rostral to a hemisection lesion were dissected and snap frozen in liquid nitrogen. Trizol was used to isolate RNA from harvested tissues, and cDNA was synthesized with Superscript III reverse transcriptase (Invitrogen) from $500 \mathrm{ng}$ of total RNA. Using random hexamer primers, RT reactions were incubated at $50^{\circ} \mathrm{C}$ for $90 \mathrm{~min}$. Each sample was RNase $\mathrm{H}$ treated $(30 \mathrm{~min}$ at $37^{\circ} \mathrm{C}$ ), followed by a $30 \mathrm{~min}$ incubation at $65^{\circ} \mathrm{C}$. Each template was used in subsequent real-time PCRs.

Real-time PCR was performed with an ABI 7000 cycler. SYBR-Green PCR master mix (Applied Biosystems) was used to monitor each amplicon, against a passive reference dye (ROX) to control for pipette errors. Each primer set was validated and showed a single peak in the dissociation curves, and amplicon size was confirmed electrophoretically (Wang and Seed, 2003) (Table 1). Relative changes in expression levels for each amplicon were normalized against glyceraldehyde-3-phosphate dehydrogenase (GAPDH) expression, each experimental group was compared against sham controls (five to seven animals each), and all reactions were performed in triplicate and repeated two times. Stated changes were quantified as changes in threshold cycle $(\Delta \mathrm{Ct})$ compared with controls $(\Delta \Delta \mathrm{Ct})$ and reported as fold changes $\left(2^{-\Delta \Delta \mathrm{Ct}}\right)$.

Flow cytometry. After infection of 26Sor cells (isolated from the spinal cords of ROSA:GFP mice), FACS was performed on a MoFlow cell cytometer (Dako) to separate GFP-positive from GFP-negative cells. Dissociated cells were suspended in HBSS supplemented with EDTA $(5 \mu \mathrm{M})$ and Penn-strep $(1 \times)$. Cell sorts were gated according to forward-scatter versus fluorescent intensity (488 $\mathrm{nm}$ excitation). After isolation, 26Sor ${ }^{\star}$ cells were grown in growth medium supplemented with pen-strep.

Data analysis. Differences among experimental groups were evaluated by a one-way ANOVA. A nonpaired Student's $t$ test evaluated differences in cell phenotypes between the $24 \mathrm{~h}$ and $7 \mathrm{~d}$ groups and real-time PCR data. For all statistical analyses, significance was accepted at a $p$ value of 0.05 and lower for a one-tailed $t$ test.

\section{Results \\ Cycling NG2 ${ }^{+}$cells produce progeny that differentiate into multiple cell types}

Ectopic gene expression by promoter-specific retroviruses has been used for decades to trace cell lineages (Brand and Perrimon, 1993; Golden et al., 1995; Cepko et al., 1998). Since cells that express NG2-proteoglycan divide after CNS insult, the regulatory sequence upstream of the NG2 protein-coding sequence was cloned (GenBank accession number DQ241507) (supplemental material, available at www.jneurosci.org) and used to construct a bicistronic retrovirus. The NG2-reporter virus was engineered such that the NG2 promoter sequence regulated the expression of GFP (EGFP), whereas the generic viral (LTR) promoter regulated AP expression. Therefore, EGFP expression marks cells that actively express NG2-proteoglycan, AP marks dividing cells generically, and cycling $\mathrm{NG}^{+}$cells are analyzed ( an EGFP ${ }^{+}$) and compared against other progenitors $\left(\mathrm{EGFP}^{-} \mathrm{AP}^{+}\right)$that respond to traumatic injury (Fig. $1 A$ ). In vitro analysis showed $91 \%$ of NG2 ${ }^{+}$ cells coexpress GFP after infection (Table 2).

An intraspinal injection of high-titer NG2-reporter virus $\left(\geq 1 \times 10^{9}\right.$ infection particles per milliliter) was injected rostral to a midthoracic hemisection of the spinal cord at $24 \mathrm{~h} \mathrm{PI}$, and the spinal cord tissue was harvested $3 \mathrm{~d}$ PI (Fig. $1 B$ ). The specificity of the reporter virus was verified by colocalization of NG2proteoglycan on $\mathrm{EGFP}^{+}$cells and quantified as a percentage of EGFP-labeled cells (Fig. 1C). NG2-proteoglycan was colocalized on $>95 \%$ of EGFP-labeled cells ( $>100$ cells per animal; $n=4$ ) (Fig. 1E). Therefore, colocalization of NG2 immunofluorescence, with EGFP, demonstrated stringent regulation of EGFP expression by the cloned NG2 promoter.

Since the NG2-reporter virus showed stringent regulation of EGFP expression, the NG2 promoter virus was used to investigate the fates adopted (molecular phenotype) by cycling NG2 ${ }^{+}$cells after SCI, in vivo. As shown previously, NG2 expression marked a large majority of dividing cells that respond to injury (Levine and Reynolds, 1999). EGFP was expressed by $32.6 \%$ of virally labeled cells (Fig. $1 D$ ). The proportion of $\mathrm{EGFP}^{+} \mathrm{AP}^{-}$versus $\mathrm{AP}^{+}$colocalization with GFAP (glial lineage), Ibal (microglial fate), and von Willebrand Factor (vWF; vascular fate) (Fig. $1 F$ ) was quantified to determine the phenotype of $\mathrm{NG}_{2}{ }^{+}$versus $\mathrm{NG}^{-}$progenitors. Surprisingly, GFAP ${ }^{+} / \mathrm{EGFP}^{+}$cells comprised $15.1 \pm$ $2.4 \%$ of the cells transfected (Fig. $1 G$ ) (five animals) by the reporter virus (Fig. $1 G$, green bars).

Historically, NG2-proteoglycan is believed to mark a single population of cycling progenitors, and $\mathrm{NG}_{2}{ }^{+}$progenitors are postulated to be unipotent OPCs that remyelinate axons after injury (Keirstead et al., 1998). Previous studies have also correlated evidence of $\mathrm{NG} 2$ coexpression with $\mathrm{GFAP}^{+}$/bromodeoxyuridine (BrdU)-positive cells (Levine and Nishiyama, 1996; Alonso, 2005) to suggest NG2 progenitors produce $\mathrm{GFAP}^{+}$cells. However, direct evidence that cycling $\mathrm{NG}_{2}{ }^{+}$cells participate in remyelination or astroglial production (or both) has yet to be published (Polito and Reynolds, 2005). Therefore, by labeling dividing cells $24 \mathrm{~h}$ after SCI, our experiments demonstrate immunofluorescent colocalization of phenotypic markers for astrocytes (GFAP), microglia (Iba1), and pericytes (vWF) on separate $\mathrm{EGFP}^{+}$cytoplasms. Since the stringency of the virus demonstrated $>95 \%$ coincident EGFP-NG2 colocalization, these data reveal that cycling cells with an active NG2 promoter express molecular markers of multiple cell types. Therefore, newborn 
A.

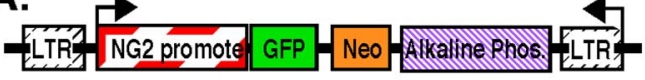

B.

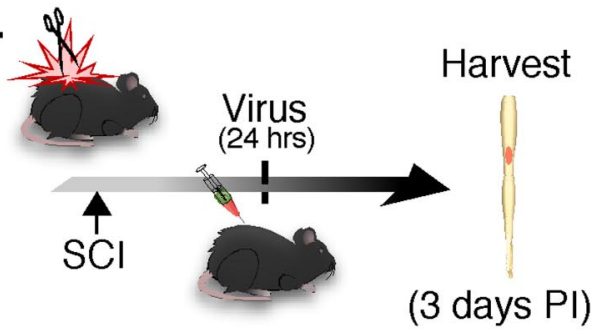

$F$.

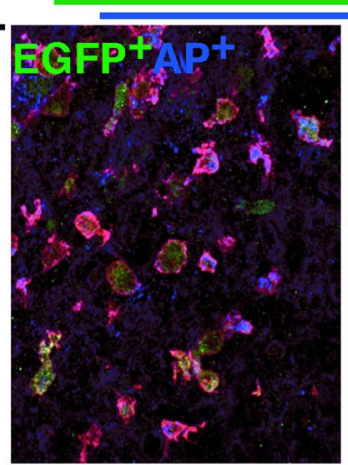

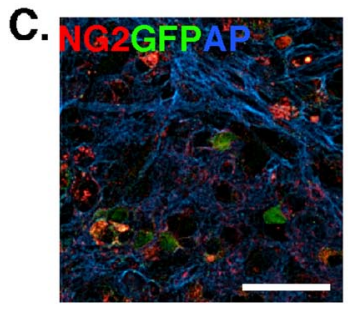

D.

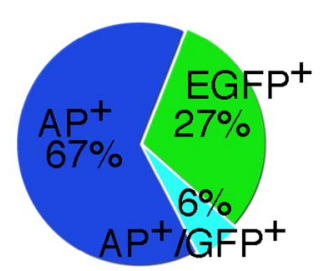

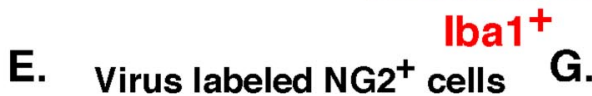

\section{G.}

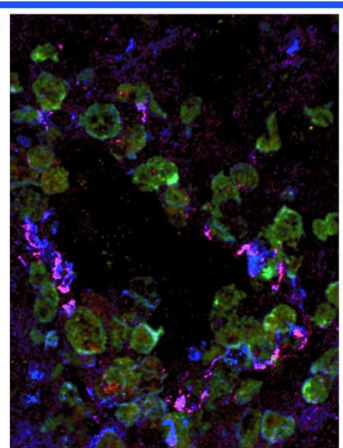

vWF $^{+}$

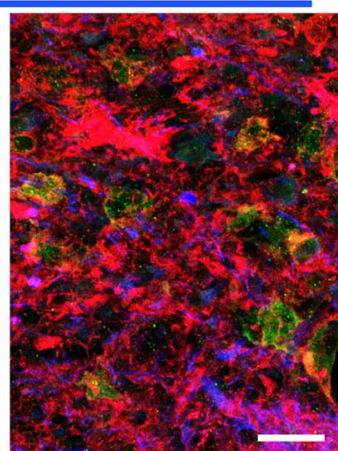

GFAP ${ }^{+}$
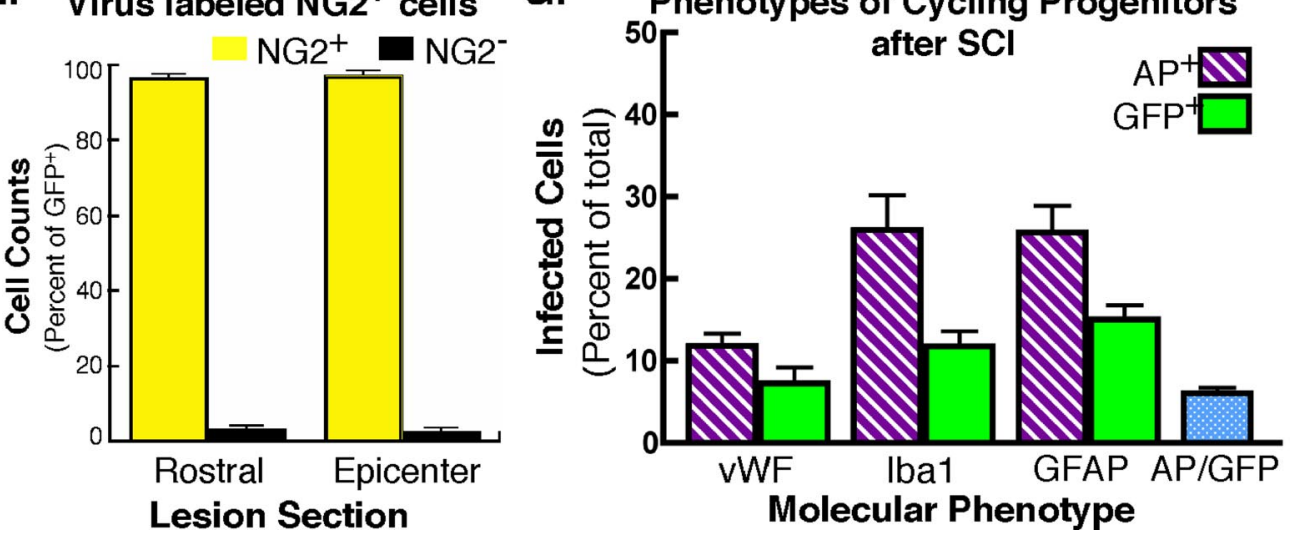

Figure 1. Cycling NG2 ${ }^{+}$cells produce multiple cell types after SCI. $A$, The NG2 promoter was used in a bicistronic retrovirus to drive the expression of EGFP, and AP (Alkaline Phos.) expression was controlled by the internal LTR. $\boldsymbol{B}-\boldsymbol{E}$, The NG2-reporter virus was used to track NG2 progenitors after injury via GFP expression $(\boldsymbol{C})$ and labeled $\sim 33 \%$ of infected progenitors $(\boldsymbol{D})$ with $>95 \%$ of EGFP-expressing cells coexpressing NG2-proteoglycan (E). EGFP expression evaluated the phenotypes of cycling NG2 ${ }^{+}$progeny. $\boldsymbol{F}$, Confocal microscopy was used to determine the molecular phenotypes of progeny derived from NG2 progenitors via colocalization of EGFP with Iba1 (microglia marker), vWF (blood-vasculature pericytes), and GFAP (glial marker). Scale bar, 10 $\mu \mathrm{m}$. G, The virally labeled cell phenotypes were quantified as a function of AP or GFP expression (3024 cells) in adjacent serial sections stained with vWF, Iba1, and GFAP. Twenty-four hours PI, the majority of cycling NG2 ${ }^{+}$cells displays a reactive phenotype $\left(\mathrm{GFAP}^{+}\right.$or $\mathrm{lba} 1^{+}$), and NG2 progenitors comprise almost $50 \%$ (combined) of reactive phenotypes $\left(\mathrm{AP}^{+} \mathrm{Iba} 1^{+}\right.$and NG2 ${ }^{+} \mathrm{Iba} 1{ }^{+} \mathrm{vs} \mathrm{AP}^{+}$and $\mathrm{NG2}{ }^{+} \mathrm{GFAP}^{+}$; microglia and astrocytes, respectively). Error bars represent SEM.

Table 2. The specificity of transgene expression by the NG2 promoter was examined by retroviral infection of adult spinal cord progenitors (aSCPs) in vitro

\begin{tabular}{lll}
\hline Transgene & Efficiency (\% infected) & Specificity $\left(\%\right.$ of NG2 $\left.{ }^{+}\right)$ \\
\hline GFP & $82.5 \pm 10.63$ & $91.8 \pm 3.73$ \\
CRE & $45.1 \pm 9.67$ & $91.2 \pm 5.12$ \\
\hline
\end{tabular}

aSCPs were infected with an NG2-reporter virus $\left(10^{5} \mathrm{cfu} / \mathrm{ml}\right)$. Three days after infection, transgene expression was interrogated by immunofluorescence. The specificity of the NG2-promoter viruses was quantified by colocalization of GFP or CRE recombinase on $\mathrm{NG2}^{+}$cells.

cells with an active NG2 promoter are not fate-restricted OPCs and thus raise two possible conclusions: cycling $\mathrm{NG}^{+}$cells are multipotent neural progenitors or NG2-proteoglycan labels several different unipotent progenitors whereby NG2-proteoglycan would not mark a single lineage. Regardless, these results demonstrate that in the setting of injury, NG2 expression is not limited to a population of fate-restricted OPCs.

Vacuolated NG2 progeny contain myelin debris within endosomes

Since EGFP expression labels the cell soma, the NG2-reporter virus was used to discern the morphologies of dividing cells that actively express NG2 and differentiate within the lesion epicenter. Unlike studies that used BrdU to label a mitotic nucleus and correlate NG2 immunoreactivity, confocal microscopy was used to visualize $\mathrm{EGFP}^{+}$somas to resolve individual cycling cells that express NG2, which revealed a subpopulation of progeny derived from cycling $\mathrm{NG}_{2}{ }^{+}$cells within the lesion epicenter. The progeny did not possess the branched multiprocess morphology previously described for NG2 progeny in the spinal cord (Horner et al., 2002). Further examination of the morphotype showed NG2 progenitor-derived progeny had large cell bodies and bore a single bifurcated process. The EGFP-expressing phenotype did not colocalize with traditional glial marker GFAP or APC (Fig. 2A). The morphotype was abundant within the lesion epicenter, and these $100 \beta^{+} \mathrm{EGFP}^{+}$progeny possessed large (5-7 $\mu$ m diameter; whole-cell examples of the morphology are highlighted by arrows, as seen via confocal $z$-plane series) vacuoles within the cell body (Fig. $2 \mathrm{~B}$ ); the vacuolated morphotype was localized within $1 \mathrm{~mm}$ of the hemisection lesion and was not detected outside the lesion epicenter. However, these vacuolated cells did not express ED1 (Fig. 2C) and could not be labeled by isolectin immunofluorescence. Instead, this novel population of NG2 progeny expressed $s 100 \beta$ (Fig. $2 C$ ), which has been shown to label alternate populations of committed astrocytes that do not express GFAP $\left(\mathrm{GFAP}^{-}\right.$) (Boyes et al., 1986; Vives et al., 2003; Jordan et al., 2007).

Since these vacuolated NG2 progeny resided within the lesion, the tissue was examined to determine whether the cells could be microglia. Within the CNS, microglia (Streit, 2000) are the only cells documented to contain large vacuoles, which are often filled with phagocytized debris (Kahn et al., 1997; Kim and de Vellis, 2005). Regardless, s100 $\beta$ did not colocalize with ED1 (macro- 

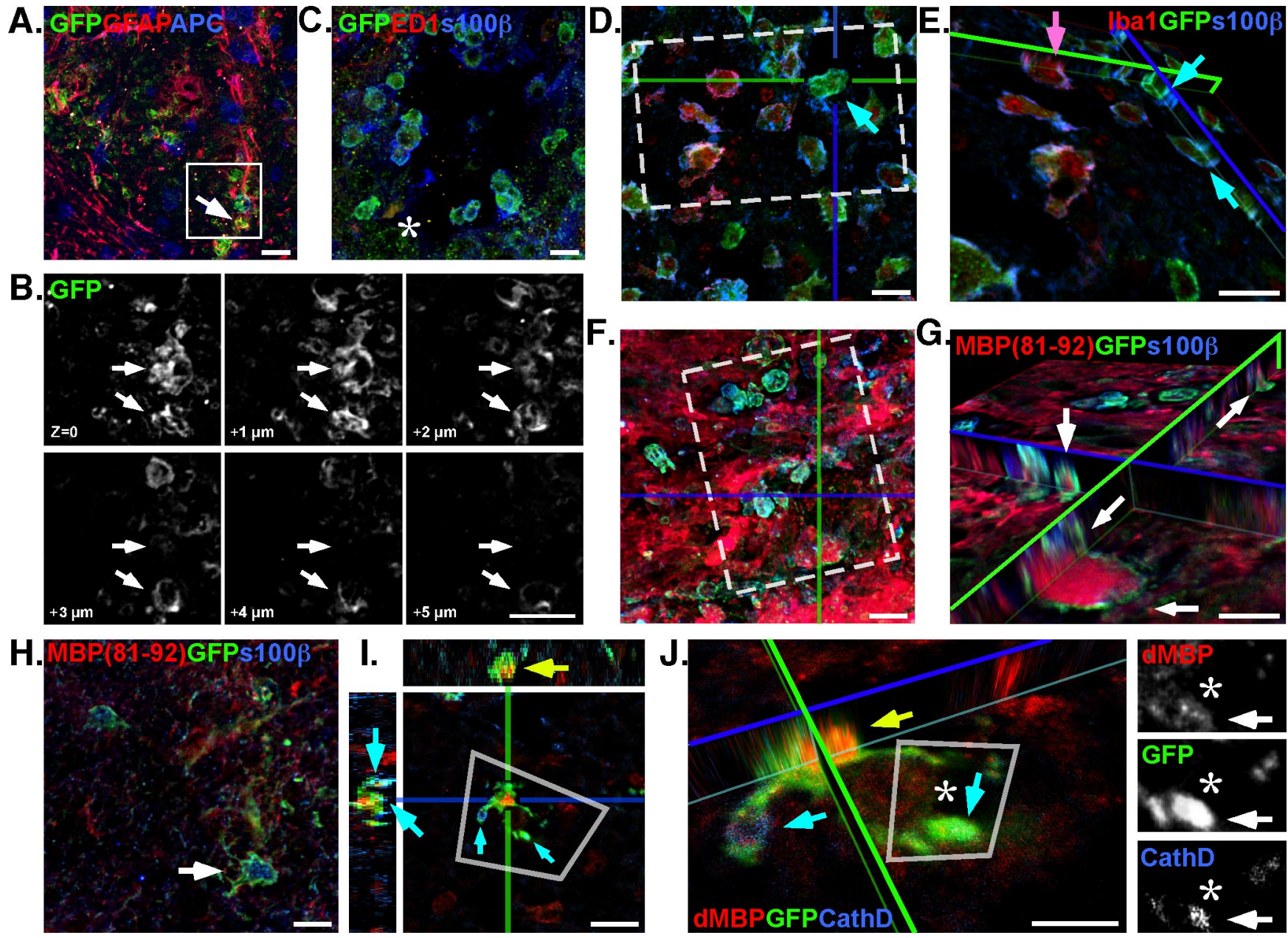

Figure 2. Progeny derived from NG2 progenitors participate in wound clearing. $A, B$, Confocal microscopy revealed a subset of cycling NG2 ${ }^{+}$cells that did not express GFAP ( $A$, arrow) and possessed large vacuoles $\left(\sim 5 \mu \mathrm{m}\right.$ ) within the cell body $(\boldsymbol{B}$, arrows; inset in $\boldsymbol{A})$. $\boldsymbol{C}$, Vacuolated EGFP ${ }^{+}$cells colocalized with s100 $\beta$ immunofluorescence but did not express ED1 (asterisk). $\boldsymbol{D}$, Adjacent serial sections show the vacuolated $5100 \beta^{+}$EGFP $^{+}$cells (cyan arrow) are a morphologically distinct population of phagocytic cell within the lesion, which are not lba ${ }^{+}$. $\boldsymbol{E}$, An orthogonal view of a confocal $z$-stackshows that vacuolated $100 \beta^{+}$EGFP $^{+}$cells (cyan arrows) do not label with other markers for phagocytic microglia (Iba1; magenta arrow). $\boldsymbol{F}$, Immunofluorescence with antibodies against dMBP (MBP 81-92) revealed the $100 \beta^{+}$progeny $\left(\mathrm{EGFP}^{+}\right)$, within the lesion epicenter, are a phagocytic phenotype and contained denature MBP within their cytoplasm. G, An orthogonal view, rotated about the $z$-axis (inset in $\boldsymbol{F}$ ), clearly shows the MBP contained within numerous EGFP ${ }^{+}$cell processes (arrows). $\boldsymbol{H}$, The vacuolated s100 $\beta$ phenotypes do not persist outside the lesion epicenter where less denatured myelin is present ( $2 \mathrm{~mm}$ rostral; arrow) and are distinct from activated $\mathrm{lba}{ }^{+}$microglia. $I$, Immunofluorescence of CathD shows colocalization (cyan arrows) of the endosome protein in cells that contain dMBP (yellow arrow). $J$, The rotated view of a confocal $z$-stack (inset in $I$ ) shows CathD localization on vacuoles and EGFP ${ }^{+}$processes (cyan arrows) that flank dMBP. Inset, Monochrome breakouts show distinct localization of dMBP within an EGFP process decorated with CathD (asterisks, arrows). Scale bars, $\sim 10 \mu \mathrm{m}$.

phage marker) (Fig. 2C) or isolectins (data not shown) in these newly discovered NG2 progeny, and a secondary stain to label Ibal confirmed that the $s 100 \beta^{+} \mathrm{EGFP}^{+}$cells comprise a population separate from the $\mathrm{Iba}^{+} / \mathrm{NG}^{+}$cells (Fig. $2 D, E$, arrows). Therefore, we concluded that these vacuolated $\mathrm{NG} 2^{+} \mathrm{s} 100 \beta^{+}$ cells are not mature microglia.

Confounded by the presence of a vacuolated nonmicroglial cell, we examined the lesion epicenter with antibodies against denatured myelin (MBP 81-92) (Gibson et al., 1984; Martenson, 1984), which labeled a sea of debris throughout the epicenter. Interestingly, myelin debris was observed within the vacuoles of the $\mathrm{EGFP}^{+} \mathrm{S} 100 \beta^{+}$cells (Fig. $2 F, G$, arrows). Confocal opticalfractionation showed intensely labeled bundles of myelin debris contained within vacuoles circumscribed by $\mathrm{EGFP}^{+}$cell bodies (Fig. $2 G$, arrows). Whereas nonvacuolated $\mathrm{EGFP}^{+}{ }^{+} 100 \beta^{+}$cells did not colocalize with MBP 81-92 rostral to the lesion site, nor did the cells possess large intracellular vacuoles (Fig. $2 H$ ).

Recently, a published astrocyte-transcriptome showed components of the endocytosis pathway (draper/Megf10 and Mertk) to be upregulated in astrocyte populations (Cahoy et al., 2008). Based on these findings, Cahoy et al. (2008) hypothesized that astrocytes are professional phagocytes. To determine whether the vacuolated NG2-progeny possessed characters of phagocytes, tissue was stained with antibodies against the endosome/lysosome protein cathepsin-D (CathD) (Westley and Rochefort, 1980) and denatured myelin basic protein $(\mathrm{dMBP})$. As revealed by confocal microscopy, $\mathrm{EGFP}^{+} \mathrm{NG} 2$ progeny do possess vacuoles decorated with CathD (Fig. $2 I$, cyan arrows). The CathD ${ }^{+}$structures are present on distinct cytoplasmic vacuoles that contain $\mathrm{dMBP}$, and CathD is seen on processes surrounding a large $\mathrm{dMBP}$ structure (Fig. $2 \mathrm{~J}$, asterisk). Therefore, $\mathrm{EGFP}^{+} \mathrm{NG} 2$ progeny differentiate into a class of phagocyte that is an $\mathrm{NG}^{+}{ }^{+} \mathrm{s} 100 \beta^{+}$astrocyte. Interestingly, alternate birth-dating studies (by virus injection at 3 and $7 \mathrm{~d}$ PI) did not label a population of cells with the phagocytic morphotype. In contrast, the population of phagocytic cells was prominent around the lesion epicenter when labeled $24 \mathrm{~h}$ PI.

CNS insults are known to induce reactive astrocytes, which provide trophic support to surrounding cells and facilitate recov- 
A
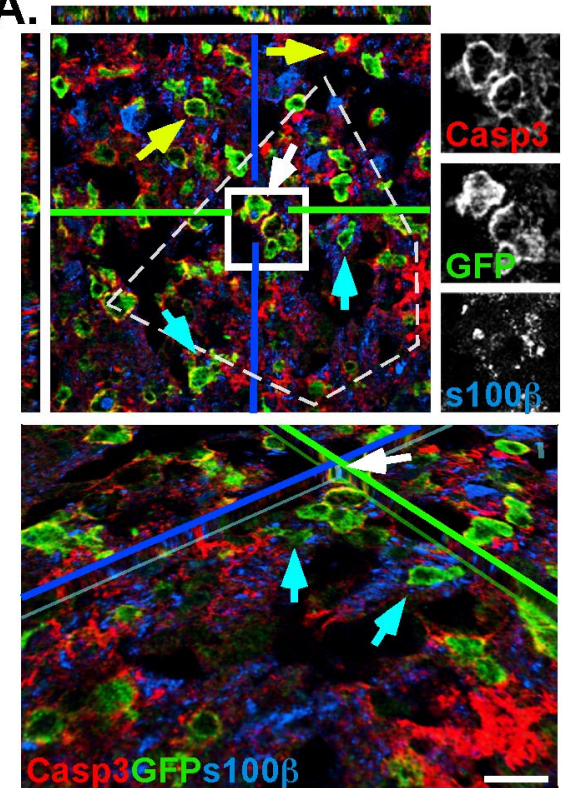

3 days $\mathrm{PI}$

C.

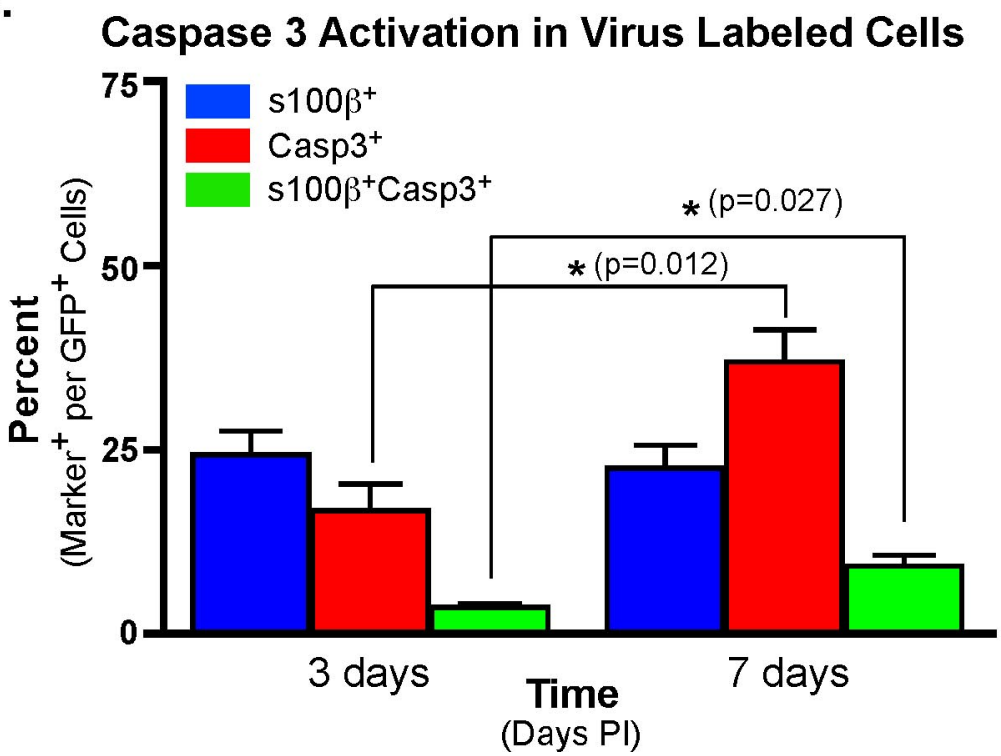

Figure 3. $\mathrm{NG}^{+}$phagocytes transition to become apoptotic $7 \mathrm{~d}$ after SCl. Immunofluorescence of virally labeled NG2 ${ }^{+}$cells, born $24 \mathrm{~h} \mathrm{PI}$, was quantified to determine whether $5100 \beta^{+}$EGFP ${ }^{+}$cells (cyan arrows) become apoptotic, since the phenotype is not seen in cells born $7 \mathrm{~d}$ PI. $\boldsymbol{A}, \boldsymbol{B}$, Confocal images of tissue harvested from animals at $3 \mathrm{~d}(\boldsymbol{A})$ and $7 \mathrm{~d}(\boldsymbol{B}) \mathrm{PI}$ was imuunofluorescently stained with antibodies against Casp3 and s $100 \beta$. Rotational views generated from each designated inset of serial sections show the morphology and colocalization of Casp3 ${ }^{+}$cells and showed a significant $\left({ }^{*} p=0.027\right)$ increase in Casp3 ${ }^{+}$s $100 \beta^{+}$EGFP $^{+}$cells (arrows) between 3 and $7 \mathrm{dPI}(\boldsymbol{C} ; 3.65 \pm 0.46 \%$ to $9.23 \pm 1.49 \%$, respectively). Overall, apoptotic cells (yellow arrow; Casp3 ${ }^{+}$) increased significantly ( $\left.p=0.012\right)$ from 3 and $7 \mathrm{dPI}(16.77 \pm 3.6 \%$ to $36.97 \pm 4.4 \%$, respectively). Scale bars, $10 \mu \mathrm{m}$. Error bars indicate SEM.

ery from traumatic injury (Eng and Ghirnikar, 1994; Aschner, 1998). Since the phagocytic astrocytes were not seen within the SCI lesion $14 \mathrm{~d}$ PI, the life span of the $\mathrm{EGFP}^{+} \mathrm{s} 100 \beta^{+}$population was examined to determine whether these NG2 progeny are transient. Furthermore, the $s 100 \beta^{+}$phagocyte was not a phenotype adopted by $\mathrm{NG}^{+}$progeny born 3 and $7 \mathrm{~d}$ PI (our unpublished observations). Therefore, SCI mice given injections of the NG2reporter virus ( $24 \mathrm{~h}$ PI) were killed at 3 and $7 \mathrm{~d}$ PI to quantify the relative number of apoptotic s100 $\beta^{+}$phagocytes. SCI tissue was stained immunofluorescently to colocalize activated (cleaved) Casp3 (apoptotic marker) with $s 100 \beta^{+} \mathrm{NG}^{+}$progeny.
$\mathrm{EGFP}^{+}{ }^{\mathrm{s}} 100 \beta^{+} \mathrm{Casp}^{+}$colocalization was quantified and used to determine the percentage of apoptotic cells at $3 \mathrm{~d}$ versus $7 \mathrm{~d} \mathrm{PI}$ (Fig. $3 A, B$ ). In general, s100 $\beta^{+} \mathrm{NG} 2^{+}$progeny born $24 \mathrm{~h}$ PI show a significant increase $(p=0.027)$ in activated Casp3 between 3 and $7 \mathrm{~d}$ PI. The percentage of apoptotic $\mathrm{EGFP}^{+}{ }^{+} 100 \beta^{+}$cells increased from $3.6 \pm$ $0.46 \%$ to $9.2 \pm 1.87 \%$ (Fig. $3 C)(n=3$ and 4 , respectively), in conjunction with an overall increase in apoptotic cells in the same time course, from $16.77 \pm 3.6 \%$ to $36.97 \pm 4.4 \%$ Casp3 $^{+}$(Fig. $\left.3 C\right)(p=0.012 ; n=4)$. The progressive increase (from 3 to $7 \mathrm{~d}$ ) in cells marked by $\mathrm{Casp}^{+}$indicates that the $\mathrm{s} 100 \beta^{+} \mathrm{NG}^{+}$progeny born at $24 \mathrm{~h} \mathrm{PI}$ is a transient population and short-lived in the PI environment. However, the interpretation that $s 100 \beta^{+} \mathrm{NG}^{+}$progeny born at $24 \mathrm{~h}$ are transient is confounded by the lack of change observed in the $\mathrm{EGFP}^{+}{ }^{+} 100 \beta^{+}$ cells between 3 and $7 \mathrm{~d}$ PI. Despite the increased number of cells with an activated Casp3, the $\mathrm{EGFP}^{+} \mathrm{s} 100 \beta^{+}$population is sustained. Therefore, a single population of labeled cells could proliferate and persist within the lesion.

NG2 progenitor differentiation profiles shift temporally as SCI

repair progresses

SCI tissue is known to undergo temporalspatial changes in cell replacement as recovery progresses after injury (Wu et al., 2005; Zai and Wrathall, 2005; Lytle and Wrathall, 2007). As such, the microenvironmental changes that evolve PI define a progressive stem cell niche. Since the NG2-reporter virus showed cycling NG2 cells produce multiple cell types, we wanted to determine whether progeny fates, as a population, shift as the PI niche recovers/regenerates. Therefore, the differentiation profile of progeny derived from NG2 progenitors born at $24 \mathrm{~h}$ and $7 \mathrm{~d}$ PI was quantified at 3 and $14 \mathrm{~d}$ PI, respectively. Dividing cells were birth-dated with the NG2-reporter virus, and the molecular phenotype was determined to discern whether the differentiation profiles shift with birthdate and correlate with temporal changes in a posttraumatic niche. Therefore, temporal-spatial changes in the stem cell niche would manifest changes in progenitor differentiation profiles as the niche recovers/regenerates PI, and thus define a progressive niche.

The temporal shift in NG2 progenitor differentiation was examined as a function of phenotype among cycling cells labeled by the NG2 virus, for cells born $24 \mathrm{~h}$ PI (analyzed $3 \mathrm{~d}$ PI) and cells born 7 d PI (analyzed 14 d PI) (Fig. 4A). Confocal microscopy was used to evaluate GFAP and APC expression in $\mathrm{EGFP}^{+}$cells born $24 \mathrm{~h}$ versus $7 \mathrm{~d}$ PI. Relative quantification of the molecular phenotypes show the majority of cycling NG2 ${ }^{+}$cells born $24 \mathrm{~h} \mathrm{PI}$ adopt an astroglial fate $3 \mathrm{~d}$ PI $\left(\mathrm{EGFP}^{+} \mathrm{GFAP}^{+}\right.$expression, 

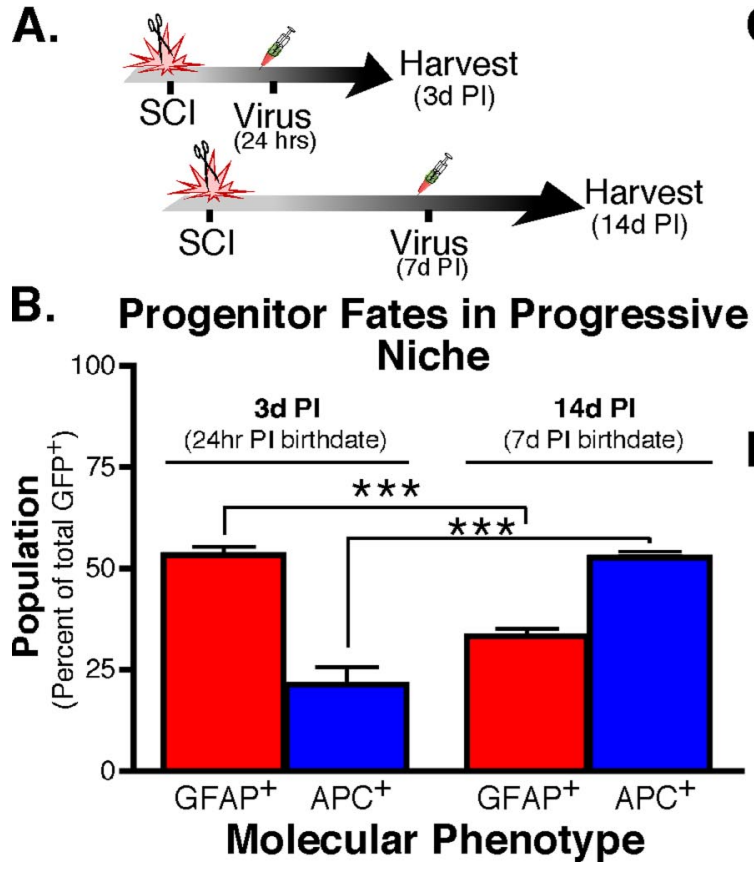
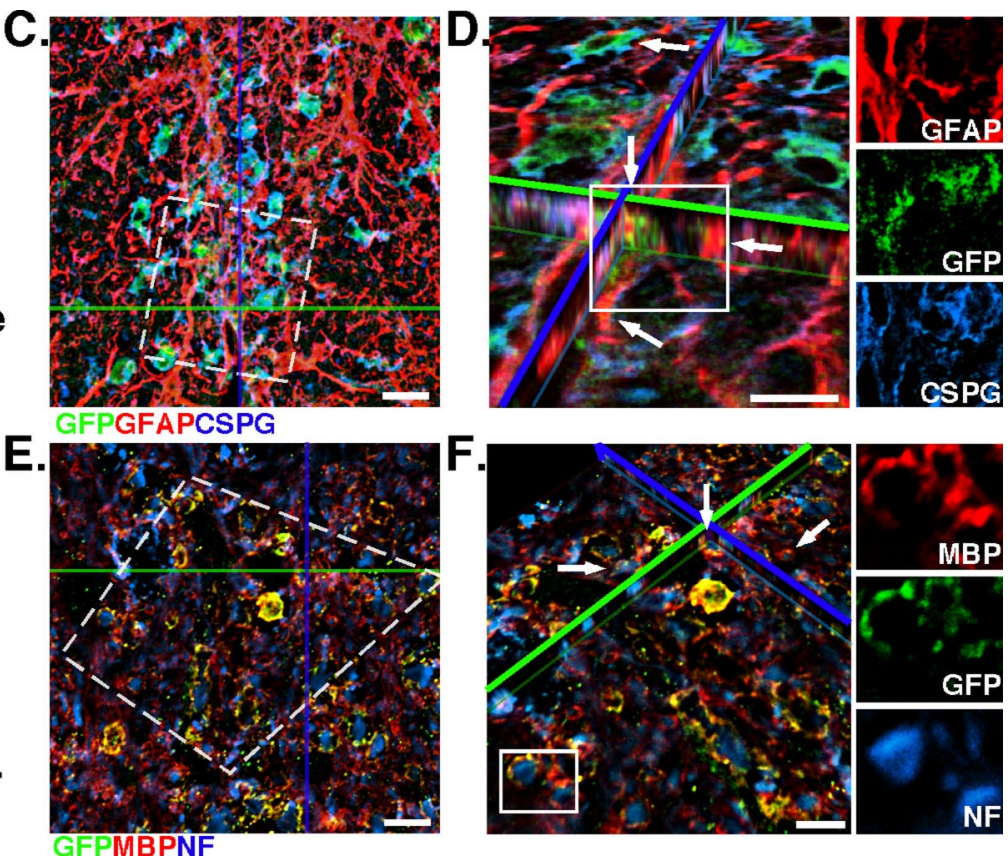

Figure 4. Progeny from cycling NG2 ${ }^{+}$cells show temporal shifts in differentiation profile after SCl. $A$, The NG2-reporter virus was used to label cycling NG2 progenitors at $24 \mathrm{~h}$ PI or $7 \mathrm{~d}$ PI. The phenotypes of the labeled cells were examined at 3 and $14 \mathrm{~d} \mathrm{PI}$. B, Fifty-three percent of the progeny derived from NG2 cells born $24 \mathrm{~h} \mathrm{PI} \mathrm{produce} \mathrm{astrocytes} \mathrm{(GFAP}{ }^{+}$) compared with $24 \%$ APC ${ }^{+}$ immature oligodendrocytes. The direction of phenotype undergoes a significant temporal shift (*** $p<0.001)$ to produce more oligodendrocytes (53\%) and fewer (35\%) when the progenitors are born $7 \mathrm{~d}$ after SCl and evaluated $14 \mathrm{~d} \mathrm{PI}$. Error bars represent SEM. C, The astrocyte progeny (born $24 \mathrm{~h} \mathrm{PI}$ ) are seen within the lesion epicenter expressing a gloitic phenotype (GFAP ${ }^{+}$and (SPG ${ }^{+}$). D, A high-resolution z-stack (tilted orthogonal view in inset in C) shows distinct colocalization of GFAP with EGFP ${ }^{+}$processes in cells born $24 \mathrm{~h}$ PI (arrows). Inset, Color channel-breakouts highlight the morphology and localization of CSPG on GFAP ${ }^{+}$cells. $\boldsymbol{E}$, Progeny derived from progenitors cycling at $7 \mathrm{~d}$ PI express MBP by $14 \mathrm{~d}$ PI. $\boldsymbol{F}, \mathrm{A}$ high-resolution z-stack (tilted orthogonal view in inset in $\boldsymbol{E}$ ) shows distinct colocalization of MBP with EGFP ${ }^{+}$processes (arrows) in cells born $7 \mathrm{~d}$ PI that encircle NF ${ }^{+}$profiles. Color channel-breakouts show an NF ${ }^{+}$profile circumscribed by an $\mathrm{EGFP}^{+} \mathrm{MBP}^{+}$process. Scale bars, $10 \mu \mathrm{m}$.

53.3\%) (Fig. 4B). Confocal micrographs of the lesion epicenter show distinct colocalization of CSPG (reactive profile) on the surface of $\mathrm{GFAP}^{+} \mathrm{EGFP}^{+}$cells derived from cycling NG2 ${ }^{+}$cells (Fig. 4C). Therefore, these newborn NG2 cells may participate in gliotic scarring within the lesion. The reactive profiles are seen within the lesion epicenter among intense GFAP immunofluorescence (Fig. 4D), which is the hallmark of gliosis and scarring (Smith et al., 1986). Therefore, the majority of NG2 progenitors born acutely ( $24 \mathrm{~h}$ ) after injury adopt a reactive fate and participate in the formation of the gliosis thought to prevent continued tissue damage after traumatic injury (Reier and Houle, 1988; Silver and Miller, 2004).

In contrast, a significant shift in phenotype is seen in $\mathrm{NG}^{+}$ progenitors cycling $7 \mathrm{~d}$ PI. Whereas acutely born cells adopt a reactive phenotype, NG2 progeny with a $7 \mathrm{~d}$ PI birthdate do not display a reactive profile after differentiation. Instead, the population dynamic of the progeny fates (derived from progenitor) undergoes a shift. Among NG2 progeny born $7 \mathrm{~d}$ PI, the progeny possess characters of early immature oligodendrocytes and express molecular markers of cells destined for an oligodendrocyte lineage $\left(52.6 \%, \mathrm{APC}^{+}\right)$versus the astroglial lineage $(33 \%$, $\mathrm{GFAP}^{+}$) (Fig. $\left.4 \mathrm{~B}\right)$. When examined at $14 \mathrm{~d} \mathrm{PI}$, confocal micrographs of progeny derived from $\mathrm{NG}^{+}$progenitors born $7 \mathrm{~d} \mathrm{PI}$ show these cells coexpress MBP (Fig. $4 E$ ). When counterstained with antibodies against neurofilaments (NFs), $\mathrm{EGFP}^{+} \mathrm{MBP}^{+}$ profiles are shown to encircle $\mathrm{NF}^{+}$structures in the dorsal columns of hemisected spinal cords (Fig. 4E, F, arrows). The presence of $\mathrm{MBP}$ on $\mathrm{EGFP}^{+}$processes demonstrates that progeny of NG2 progenitors are able to produce oligodendrocytes, which have the potential to participate in remyelination; however, additional studies that examine myelin profiles are needed to pro- vide unequivocal evidence that NG2 progeny remyelinate axons after injury. Regardless, the temporal shift in adopted fates demonstrates that $\mathrm{NG}_{2}{ }^{+}$progenitors produce multiple cell types after injury. Furthermore, the fates adopted by endogenous cycling $\mathrm{NG}^{+}$cells are influenced by temporal and spatial cues within the progressive niche, and thus the product of the progeny is contingent on the nurturing derived from the PI niche.

\section{Instructive cues with the PI niche evolve to direct}

progenitor differentiation

Behavioral recovery is known to be minimal within the first $7 \mathrm{~d}$ after SCI. However, in the second and third weeks (7-21 d PI), animals show the greatest changes in behavioral recovery (Ma et al., 2001). Since we observed a temporal shift in the differentiation profiles of cycling endogenous $\mathrm{NG}_{2}{ }^{+}$progenitors that parallels the progression in behavioral recovery seen in SCI animals, we hypothesized that instructive cues within the niche must evolve temporally to promote astrocyte and oligodendrocyte differentiation PI. Therefore, we examined the transcriptional profile of molecules that direct BMP signaling and oligogenesis in the SCI niche. After exsanguinations, mRNA was isolated from a 1 mm block of tissue (rostral edge of the lesion and T9 from controls). Quantitative real-time PCR was used to examine the transcriptional profile of each gene set at $24 \mathrm{~h} \mathrm{PI}$ and $7 \mathrm{~d} \mathrm{PI}$ (relative to GAPDH expression) to determine whether changes in the molecular cues precede concomitant temporal shifts in progeny fates after SCI.

The antagonistic action of BMP and noggin control glial differentiation (astrocytic versus oligodendrocytic fate, respectively) throughout development, and noggin maintains stemness within neurogenic regions of the adult brain (Lillien and Raphael, 
A.

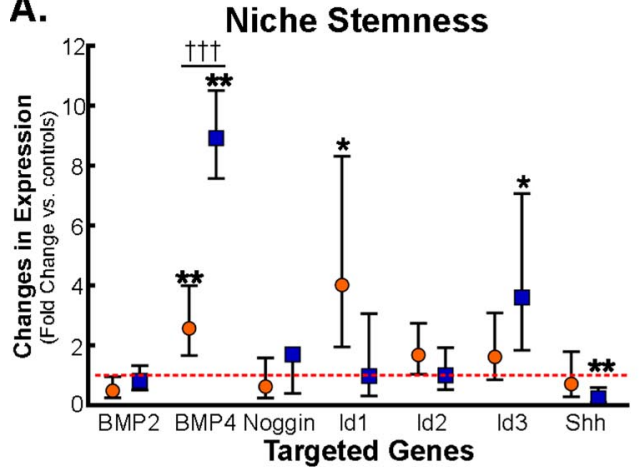

B.

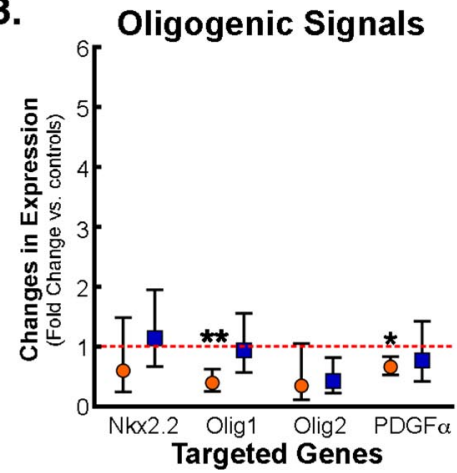

C.

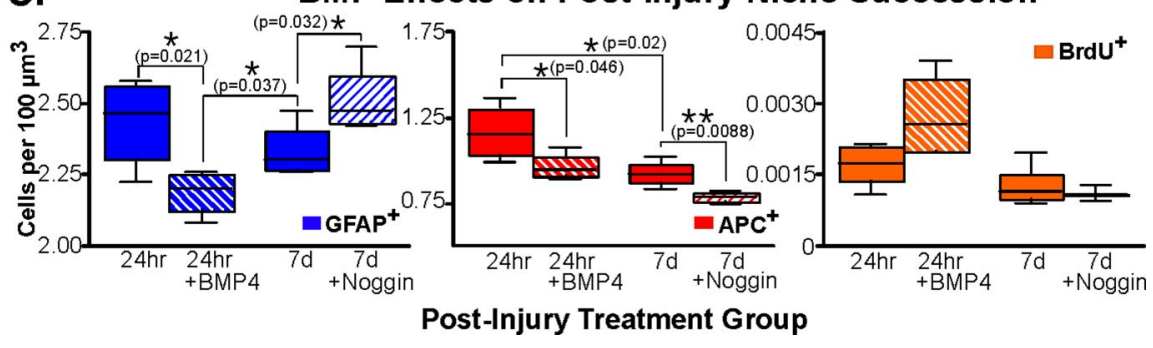

Figure 5. Temporal shifts in the expression of molecular cues and BMP ligand injection modulate gliogenesis in the PI niche. Real-time PCR on CDNA derived from injurious tissue ( $24 \mathrm{~h}$ or $7 \mathrm{~d} \mathrm{Pl}$; orange and blue symbols, respectively) quantified the difference in expression of 17 genes. The fold change in gene expression is expressed as the difference in threshold cycle compared with GAPDH expression of experimental versus control values ( $24 \mathrm{~h}$ or $7 \mathrm{~d} \mathrm{Pl}$; circles and squares, respectively). $A$, BMP4 expression is elevated 2.5 -fold at $24 \mathrm{~h} \mathrm{PI}$ and continues to increase by $7 \mathrm{~d} \mathrm{PI}$ (8.9-fold), which could influence the increase in early Id1 expression $24 \mathrm{~h} \mathrm{PI}$ (up 2-fold). Whereas Id3 becomes elevated 3.6-fold by $7 \mathrm{~d}$ PI and Shh expression is suppressed $80 \%(0.24$ of controls), Id 2 did not change significantly. $\boldsymbol{B}$, Factors known to be necessary for oligodendrocyte differentiation have reduced expression levels $24 \mathrm{~h} \mathrm{PI}$ (0lig1, PDGF $\alpha$ ) but return to control levels by $7 \mathrm{~d}$ PI to facilitate remyelination. ${ }^{*} p=0.05 ;{ }^{* *} p<0.01$; ${ }^{\mathrm{t+}} p<0.001$ by $t$ test. Error bars represent SEM. C, BMP signaling was modulated in SCl by direct injection of BMP4 (24h PI) and noggin (7 d PI). Gliogenesis (GFAP ${ }^{+}$and $\mathrm{APC}^{+}$cells) was reduced significantly $(p=0.021)$ in BMP4-injected animals. noggin increased astrogliogenesis (GFAP ${ }^{+}$) but decreased overall numbers of oligodendrocytes ( $\mathrm{APC}^{+}$) in animals injected $7 \mathrm{~d}$ PI. Cell proliferation was not affected by BMP4 or noggin (statistics determined by one-tailed $t$ test; error bars represent SEM).

2000; Lim et al., 2000). Interestingly, noggin expression is only slightly diminished at $24 \mathrm{~h} \mathrm{PI}$ and increased at $7 \mathrm{~d} \mathrm{PI}$, but noggin expression does not differ significantly from levels seen within the intact spinal cord. In contrast, BMP4 expression is increased 2.57-fold (Fig. 5A) $(p<0.05)$ at $24 \mathrm{~h} \mathrm{PI}$ and 8.9-fold $7 \mathrm{~d} \mathrm{PI} \mathrm{(Fig.}$ $5 A)(p<0.01)$.

BMPs are thought to regulate stemness by regulating the expression of inhibitors of differentiation and factors that promote progenitor self-renewal (Alvarez-Buylla and Lim, 2004). Since the upregulation of BMP4 persisted between $24 \mathrm{~h}$ and $7 \mathrm{~d} \mathrm{PI} \mathrm{(Fig.}$ $5 A)\left({ }^{\dagger \dagger} p<0.0001\right)$, we quantified the secondary effects on the expression profile of inhibitors of DNA binding/differentiation (Id transcription factors) and Shh (which promotes selfrenewal). Significant genomic shifts are observed for both Id1 and Id3. Id 1 is elevated 4.1 -fold $(p<0.05) 24 \mathrm{~h} \mathrm{PI}$ and returns to control levels by $7 \mathrm{~d}$ PI, whereas Id3 does not become elevated until $7 \mathrm{~d}$ PI (3.6-fold; $p<0.05)$. Changes in Id 2 expression are modest (1.6-fold at $24 \mathrm{~h} \mathrm{PI}$ ) and do not vary significantly from controls, and Shh expression is reduced to 0.23 -fold at $7 \mathrm{~d} \mathrm{PI} \mathrm{(Fig.}$ $5 A)(p<0.01)$. Since Ids are known to affect stem cell fate (Ying et al., 2003), the expression profile suggests a possible mechanism for antagonism between Id1, Id3, and Shh expression. The orchestrated actions of Ids and Shh highlight a temporal shift for instructive cues within the niche that promote self-renewal toward cues that promote terminal differentiation of progenitors into astrocytes and oligodendrocytes to facilitate recovery (Tzeng et al., 1999).
The progression of the instructive niche from a pro-proliferation to prodifferentiation between $24 \mathrm{~h}$ and $7 \mathrm{~d}$ PI, respectively, indicate a potential niche progression to explain the observed shift in the fate of $\mathrm{NG}_{2}{ }^{+}$progeny toward oligodendrocyte production. Previous studies have demonstrated how NG2 progenitors that express PDGF $\alpha$ receptor produce oligodendrocytes and that NG2 cells must divide and differentiate to facilitate recovery after demyelination lesions (Keirstead and Blakemore, 1999; Hampton et al., 2004). In addition, the expression and subcellular localization of basic helix-loop-helix transcription factors (Olig1 and Olig2) are known to regulate oligodendrocyte differentiation to meet repair demands (Arnett et al., 2004). Therefore, the expression profile of Nkx2.2, Olig1, Olig2, and PDGF $\alpha$ was evaluated to determine whether an increase in pro-oligodendrocyte cues accompanied the observed changes in differentiation cues (Id and Shh) within the instructive niche.

Real-time PCR experiments revealed reduced Olig1 (0.39-fold; $p<0.01)$ and PDGF $\alpha$ (0.66-fold; $p<0.05)$ expression in the acute PI niche (24 h PI) (Fig. 5B). Expression levels recovered, and by $7 \mathrm{~d} \mathrm{PI}$, Olig 1 and PDGF $\alpha$ expression mirrored expression levels with the intact niche (control). However, Nkx2.2 and Olig2 expression did not change significantly within the PI niche at $24 \mathrm{~h}$ or $7 \mathrm{~d}$ PI. Combined, the observed changes in cues that affect proliferation and/or differentiation highlight changes that evolve within the progressive niche to orchestrate oligodendrocyte differentiation PI, in accord with the state of repair.

\section{BMP signals modulate gliogenesis in the PI niche}

Since BMP4 transcription showed persistent upregulation after injury, and since other studies have shown that BMP signaling maintains the subventricular zone stem cell niche (Lim et al., 2000), experiments were designed to examine how BMP signals affect the PI niche. To augment signaling, BMP4 (50 $\mu \mathrm{g} / \mathrm{ml})$ was injected into the $24 \mathrm{~h}$ PI lesion to supplement BMP4 concentrations and mimic the $7 \mathrm{~d}$ PI BMP4 transcriptional state. In the $7 \mathrm{~d}$ PI lesion, BMP signaling was antagonized by a single injection of noggin $(50 \mu \mathrm{g} / \mathrm{ml})$. Therefore, BMP4 protein would be upregulated early and suppressed $7 \mathrm{~d}$ PI, to oppose the PI dynamics (for BMP4) shown by quantitative PCR.

To measure how BMP signals remodel the PI niche, the total number of astrocytes and oligodendrocytes was quantified in SCI tissue at $24 \mathrm{~h}$ PI versus $7 \mathrm{~d}$ PI with BMP 4 and noggin supplementation. BMP4 injection into the SCI lesion $24 \mathrm{~h}$ PI significantly reduced the number of $\mathrm{GFAP}^{+}$cells in the PI niche (lesion epicenter, $2 \mathrm{~mm}$ rostral, and $2 \mathrm{~mm}$ caudal). Compared with controls, BMP4-injected animals had a $10 \%$ reduction in astrogliogenesis (Fig. $5 C$ ) (2.189 cells vs 2.435 cells $/ 100 \mu \mathrm{m}^{3} ; p=0.021$; $n=4)$, and BMP4 reduced $\mathrm{GFAP}^{+}$cells at $24 \mathrm{~h} \mathrm{PI}$ below $7 \mathrm{~d} \mathrm{PI}$ controls (Fig. $5 C)(p=0.037 ; n=4)$. noggin, however, increased 
A.
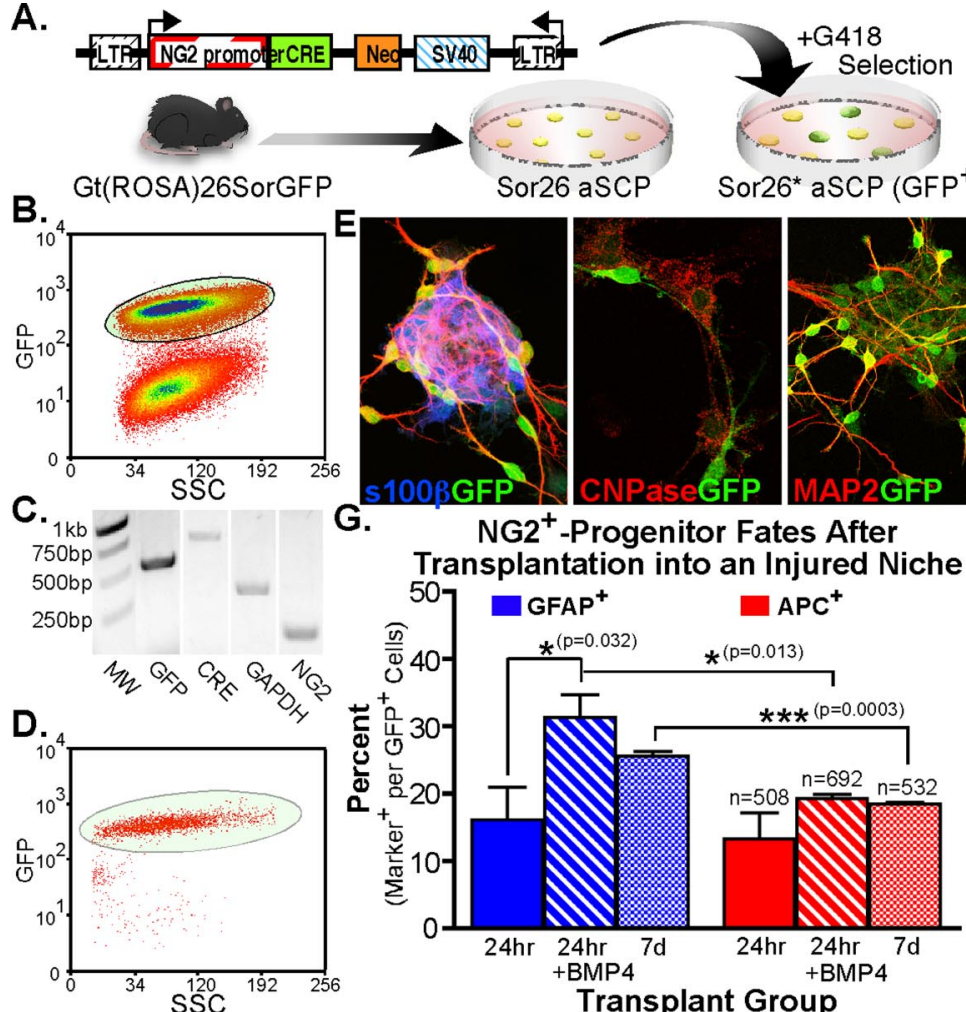

Sor26 aSCP

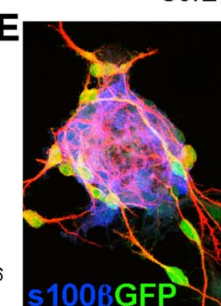

G.

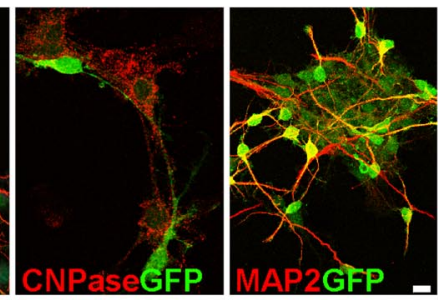

$\mathrm{NG2}^{+}$-Progenitor Fates After Transplantation into an Injured Niche

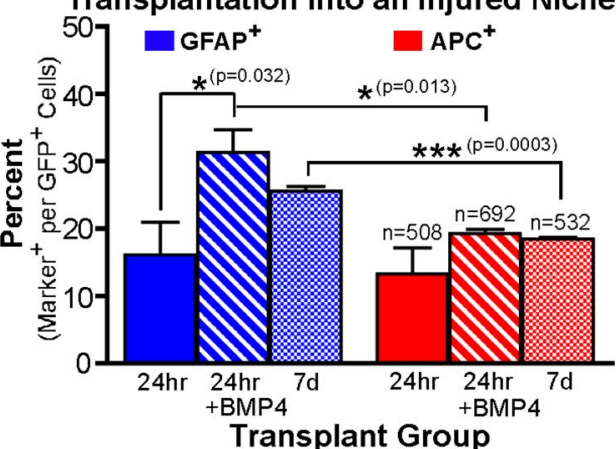

F.
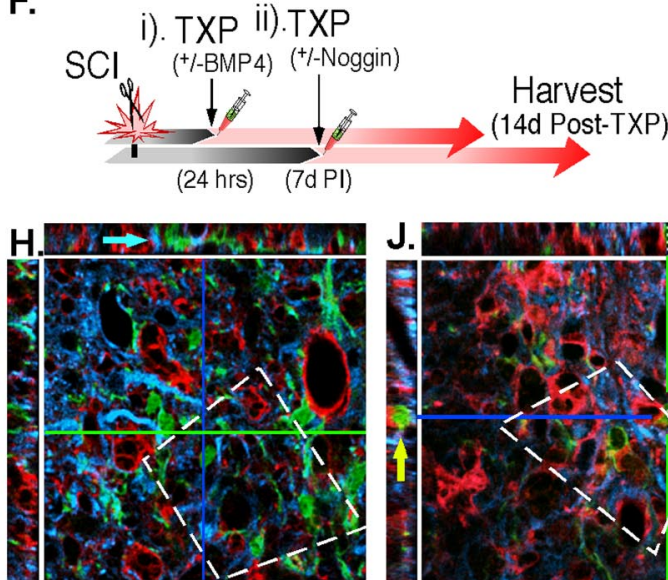

I.

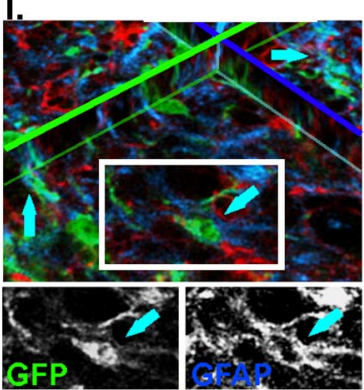

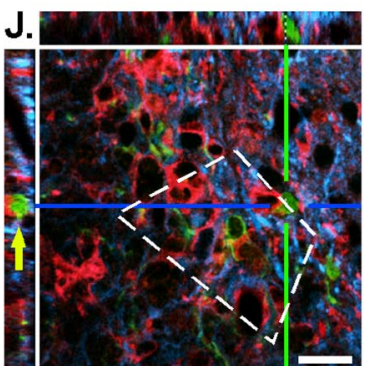

K. GFPAPCGFAP

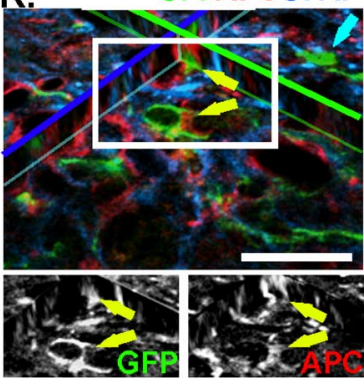

Figure 6. NG2 progenitors respond to BMP4 when transplanted into a progressive niche. $A$, The NG2 promoter was used to drive the expression of CRE recombinase and infect spinal cord progenitors isolate from ROSA::GFP mice (26Sor cells). $\boldsymbol{B}$, After infection, induced GFP expression was analyzed by activated fluorescence, and cells (26Sor* cells) were purified via FACS (EGFP high). C, mRNA isolated from 26Sor* cells confirmed CRE expression in cells that express NG2 and EGFP [shown with molecular weight markers (MW)]. D, Sor26* cells were amplified in cell culture and analyzed, via FACS, before transplantation into SCI. $E$, The stemness of 265 Sor ${ }^{*}$ cells was examined under differentiation conditions to produce the s100 $\beta^{+}$astrocyte, CNPase ${ }^{+}$oligodendrocyte, and $\mathrm{Map2}^{+}$neuronal phenotypes. $\boldsymbol{F}$, Hemisection-SCl animals received transplants of 265 or* cells at $24 \mathrm{~h}$ and $7 \mathrm{~d} \mathrm{PI} \mathrm{(with} \mathrm{and} \mathrm{without} \mathrm{BMP4).} \mathrm{The} \mathrm{differentiation} \mathrm{profile} \mathrm{of} \mathrm{transplanted} 2650{ }^{*}$ was examined $14 \mathrm{~d}$ after transplantation (TXP). $\mathbf{G}$, BMP4 increased the percentage GFAP ${ }^{+} 26 \mathrm{Sor}^{*}$ cells $(31.3 \% ; \boldsymbol{H}, \boldsymbol{I}$, cyan arrows), compared with naive controls $(16.1 \%$; $\boldsymbol{J}, \boldsymbol{K})$, to exceed the percentage of GFAP ${ }^{+}$cells in animals that received transplants at $7 \mathrm{dPI}\left(25.6 \% ;{ }^{* * *} p=0.032\right)$. BMP4 did not alter the percentage of $\mathrm{APC}^{+} 26 \mathrm{Sor}{ }^{*}$ cells (yellow arrows) significantly (statistics determined by one-tailed $t$ test). Rotated views of confocal $z$-plane stacks ( $\boldsymbol{I}$ and $\boldsymbol{K}$ from $\boldsymbol{H}$ and $\boldsymbol{J}$, respectively) showed increases in the proportions of GFAP colocalization $(\boldsymbol{I})$ versus APC $(\boldsymbol{K})$ on $26 \mathrm{~S}$ or* cells transplanted with BMP4 $24 \mathrm{~h} \mathrm{PI.} \mathrm{Monochrome} \mathrm{breakouts} \mathrm{(from} \mathrm{insets)} \mathrm{show} \mathrm{distinct} \mathrm{localization} \mathrm{of} \mathrm{GFAP} \mathrm{and} \mathrm{APC} \mathrm{with} \mathrm{EGFP}{ }^{+}$processes (cyan and yellow arrows, respectively). Scale bars, $\sim 10 \mu \mathrm{m}$. Error bars represent SEM.

the total number of GFAP ${ }^{+}$cells in the PI niche at $7 \mathrm{~d}$ PI (Fig. 5C) ( 2.516 cells vs 2.337 cells $/ 100 \mu \mathrm{m}^{3} ; p=0.032 ; n=4$ ).

An examination of the oligodendrocyte population showed BMP4 had similar effects on the number of $\mathrm{APC}^{+}$cells within the PI niche. In control animals, the pool of oligodendrocytes was diminished $21 \%$ between $24 \mathrm{~h}$ and $7 \mathrm{~d}$ PI (1.171 cells to 0.929 cells $\left./ 100 \mu \mathrm{m}^{3} ; p=0.02 ; n=4\right)$, which corroborates previously reported data (McTigue et al., 2001). Similarly, $\mathrm{APC}^{+}$populations are reduced $17 \%$ in animals intraspinally injected with BMP4 at $24 \mathrm{~h}$ PI (Fig. $5 C)\left(0.970\right.$ cells vs 1.171 cells $/ 100 \mu \mathrm{m}^{3} ; p=$ $0.046 ; n=4)$, which is equivalent to the $\mathrm{APC}^{+}$population numbers at $7 \mathrm{~d}$ PI. In contrast to its effect on $\mathrm{GFAP}^{+}$cells, noggin reduced the number of $\mathrm{APC}^{+}$cells present in PI tissue at $7 \mathrm{~d}$ (Fig. 5C) $(p=0.0088 ; n=4)$.

Since glial numbers showed a consistent reduction in BMPinjected animals, cell proliferation was quantified to ensure that the observed reduction in gliogenesis was not a secondary side effect of reduced cell replacement (via proliferation). All animals received intraperitoneal injections of $\mathrm{BrdU}(50 \mu \mathrm{g} / \mathrm{kg})$ in conjunction with the intraspinal injections of BMP4 or noggin. BrdU immunoreactivity was quantified within the lesion epicenter and $2 \mathrm{~mm}$ rostral and caudal (as with GFAP and APC stereology). In each experimental group, proliferation was consistent and did not vary from controls at $24 \mathrm{~h}$ or $7 \mathrm{~d} \mathrm{PI} \mathrm{(Fig.} \mathrm{5E).} \mathrm{Therefore,} \mathrm{the}$ changes in gliogenesis were attributable to BMP4's ability to af- fect differentiation and create shifts in cell populations rather than reduce cell numbers overall by reducing cell proliferation.

\section{BMP signals modulate NG2 progenitor differentiation in the PI niche}

The observed changes in glial populations, within the progressive niche, suggest that BMPs could serve to direct progenitor differentiation to facilitate lesion repair. Therefore, we performed transplantation experiments to determine whether BMP4 supplements induce NG2 progenitors to adopt a differentiation profile similar to naive cells transplanted $7 \mathrm{~d}$ PI. A CRE recombinase expression retroviral vector, constructed with the NG2 promoter, was used to infect CNS progenitors isolated from adult 129Gt(ROSA)26Sor ${ }^{\text {tm2Sho } / J}$ mice (ROSA:GFP:26Sor cells) spinal cords. According to the paradigm, progenitors that express NG2proteoglycan will express CRE and induce GFP to be expressed in cells with an active NG2 promoter (Fig. $6 \mathrm{~A}$ ), and thus produce a lineage of CNS-derived NG2-progenitors labeled by EGFP for transplantation (Table 2.).

After viral infection with the NG2-CRE virus, the proportion of CNS progenitors that express NG2-proteoglycan was determined by activated fluorescence and subsequently used to separate GFP-positive and -negative 26Sor progenitors. After 2 weeks of G418 selection and amplification, FACS analysis showed $\sim 28.5 \%$ GFP-positive cells (26Sor ${ }^{\star}$ cells) (Fig. $6 B$ ), and mRNA 
analysis by RT-PCR showed CRE and NG2 expression in GFP ${ }^{+}$ cells (Fig. 6C). After expansion in culture, 26Sor ${ }^{\star}$ cultures maintained GFP expression (Fig. 6D). 26Sor ${ }^{\star}$ cells displayed the morphology and expressed phenotypic markers of glia (GFAP), neurons (TuJ1, Map2), and oligodendroglia (CNPase) when exposed to differentiation medium (Fig. 6E). Therefore, as seen with the NG2-reporter virus in SCI, NG2-proteoglycan was expressed by progenitors with the potential to produce multiple cell types and morphologies and corroborate multiple cell types observed in vivo with the NG2-reporter virus (above).

Given the potential to produce a diverse array of progeny, akin to endogenous cycling NG2 ${ }^{+}$cells, we quantified the phenotypic profile adopted by 26 Sor $^{\star}$ cells transplanted at $24 \mathrm{~h}$ versus $7 \mathrm{~d}$ PI. Whereas experiments discussed above (Fig. 1) quantified viruslabeled cycling $\mathrm{NG}_{2}{ }^{+}$cells of a nonspecific origin, direct transplantation of 26Sor ${ }^{*}$ cells into the lesion epicenter enables niche effects on an NG2 progenitor, of a known differentiation potential and origin to be examined directly. Cells transplanted at $24 \mathrm{~h}$ PI had no fate bias, and an equal percentage of transplanted cells expressed GFAP $(16.1 \pm 4.8 \%)$ versus APC (13.3 $\pm 3.9 \%)$ (Fig. $6 G)(n=4$ and 3, $n=508)$. However, 26Sor ${ }^{\star}$ cells transplanted $7 \mathrm{~d}$ PI displayed a surprising differentiation profile. Contrary to virally labeled cycling $\mathrm{NG}_{2}{ }^{+}$cells, which showed a shift toward an $\mathrm{APC}^{+}$phenotype in cells born $7 \mathrm{dPI}, 26$ Sor $^{\star}$ cells transplanted $7 \mathrm{~d}$ PI had a higher percentage of $\mathrm{GFAP}^{+}$cells $(25.6 \pm 0.66 \%)$ compared with $\mathrm{APC}^{+}$cells $(18.5 \pm 0.27 \%) 14 \mathrm{~d}$ after transplantation (Fig. $6 G)(p=0.0003 ; n=3, n=532)$.

Since BMP ligands induced changes in the cellular composition of the PI niche (Fig. 5C), in addition to the increase in BMP4 transcription (Fig. $4 B$ ) and coincident shift in the differentiation profile of progenitors born after SCI (Fig. 5A), we hypothesized that BMP ligands (administered at the time of transplantation) would shift the differentiation profiles of transplanted 26Sor* cells. Specifically, we hypothesized that BMP4 at $24 \mathrm{~h}$ PI would induce a profile similar to naive $7 \mathrm{~d}$ transplants. Indeed, despite the split in phenotype, BMP4 induced 26Sor ${ }^{\star}$ cells transplanted at $24 \mathrm{~h} \mathrm{PI} \mathrm{(Fig.} 6 \mathrm{H}, \mathrm{I})$ to adopt a differentiation profile that mimicked naive $7 \mathrm{~d}$ PI transplants, instead of $24 \mathrm{~h}$ PI naive transplants (Fig. 6J,K). Compared with the unbiased phenotype split among $24 \mathrm{~h}$ PI transplants, BMP4 significantly increased the percentage of GFAP ${ }^{+}$cells $(31.3 \pm 3.4 \%)$ versus $\mathrm{APC}^{+}$cells $(19.3 \pm 0.61 \%)$ (Fig. $6 G)(p=0.13, n=3, n=692)$. Together, these data demonstrate that BMP4 has an appreciable ability to remodel the PI stem cell niche and, in the process, BMP4 is able to modulate the fate choice of NG2-expressing progenitors.

\section{Discussion}

Cell genesis after spinal cord injuries is well documented (Fawcett and Asher, 1999; McTigue et al., 2001; Zai and Wrathall, 2005; Horky et al., 2006); however, surprisingly little data describe how progenitor cell fate is instructed and what signals drive the PI niche as it evolves. This has been attributable in part to the ambiguous nature of assaying progenitor cell lineage by histochemical methods alone. In an injury environment, dying cells, proteases, and Igs create aberrant protein distributions and nonspecific signals that confound the identification of normally detectable epitopes. This challenge has driven the development of viral and genetic methods to isolate and follow glial progenitor cell lineages based on expression of lineage-specific pathways (Belachew et al., 2003; Aguirre et al., 2007; Meletis et al., 2008; Zhu et al., 2008). The studies herein are the first to use a unique NG2-reporter virus to demonstrate a coordinated temporal shift in phenotypes adopted by progenitors that express NG2- proteoglycan. This novel tool revealed a unique subpopulation of cells derived from NG2-expressing cells that produce phagocytic s $100 \beta^{+}$cells shown to contain denatured myelin within endosomes. The transcriptome of the PI niche was characterized and showed temporal fluctuations in regulatory genes, such as BMP, that coincide with shifts in the differentiation profiles observed for NG2 progenitors after SCI.

The fates adopted by cycling $\mathrm{NG}^{+}{ }^{+}$cells indicate a temporal shift occurs within the PI niche to direct a transition in progenitor differentiation between $24 \mathrm{~h}$ and $7 \mathrm{~d}$ PI. By using a reporter virus to label cells actively expressing NG2-proteoglycan, these studies are the first to be able to address the fates adopted by $\mathrm{NG}^{+}$ progenitors. Since the cytoplasm of cells with an active NG2 promoter are labeled by EGFP, cycling $\mathrm{NG}^{+}{ }^{+}$cells could be identified as $\mathrm{GFAP}^{+}$and $\mathrm{APC}^{+}$expression by direct association with a particular cytoplasm rather than coincident localization with NG2-proteoglycan in the extracellular milieu. As a result, the studies revealed progenitors born $24 \mathrm{~h}$ PI are gliotic, coexpress CSPGs, and participate in scar formation, whereas $\mathrm{NG}_{2}{ }^{+}$cells born $7 \mathrm{~d}$ PI produce a greater proportion of cells that coexpress APC, which we hypothesize could participate in the functional recovery that coincides with the transition in behavioral recovery in SCI animals observed by Ma et al. (2001). Furthermore, the reporter virus has been the first study to provide evidence of direct colocalization of MBP on a cell with an active NG2 promoter.

As a tissue recovers from injury, we show that molecular cues, known to instruct progenitors, undergo a temporal shift between $24 \mathrm{~h}$ and $7 \mathrm{~d}$ PI. Experiments in culture have demonstrated BMPs induce Id expression to affect astrogliogenesis versus oligodendrocyte lineage commitment (Yanagisawa et al., 2001; Samanta and Kessler, 2004). Our results demonstrate that Id1 and Id3 transcription undergoes a temporal shift that correlates with the shift in lineage commitment after SCI. The delayed increase in Olig1 and PDGF $\alpha$ may reflect the trend toward an oligogenic niche, which correlates with the observed shifts in fates adopted by cycling $\mathrm{NG}^{+}$progenitors from the acute astrocytic fate to produce oligodendrocytes. Combined, the data suggest a model for succession in a progressive progenitor niche: acute signals generated within $24 \mathrm{~h}$ aid the rescue response whereby endogenous neural progenitors respond to produce astroglia to facilitate blood-brain barrier repair and preserve tissue integrity. Subsequent differentiation cues progress temporally to facilitate niche repair by directing latent progenitors (i.e., $7 \mathrm{~d}$ PI birthdate) to produce a greater proportion of oligodendrocytes to repair myelin. Thus, as the PI niche recovers, the progressive niche directs cycling NG2 cells to produce astrocytes or oligodendroglia in a regimented process.

In addition, these experiments are the first to show reactive astrocytes (derived from cycling $\mathrm{NG}^{+}$cells) as phagocytes within the acute PI niche. Recent analysis of the astrocytetranscriptome showed increased expression of phagocyte genes (Cahoy et al., 2008), but for the first time, our studies show images of a class of reactive astrocyte ( $100 \beta$ expressing) with myelin debris contained within endosomes $\left(\right.$ CathD $\left.^{+}\right)$. Astrocytes have a demonstrated role in tissue homeostasis (Aschner, 1998), and immature astrocytes have been shown to phagocytize boutons in development (Ronnevi, 1978), but how an astrocyte participates to restore homestasis in a PI environment is not known. More recently, quiescent multipotent $\mathrm{s} 100 \beta$ astrocytes have been shown to exist after a stab wound in the brain (Buffo et al., 2008). Although the cells identified by Buffo et al. (2008) did not express $\mathrm{NG} 2$, the quiescent astrocytes proliferated and participated in 
reactive gliosis after injury. Our studies have revealed another class of s100 $\beta$-expressing cell that does not express a phenotypic marker of peripheral cells and provides the custodial function of phagocytosis before the arrival of peripheral monocytes (Popovich and Hickey, 2001). Future work on this unique astrocyte progenitor will be needed to better understand its role in removal of debris after injury.

Subsequently, after intraspinal injection of BMP4, transplanted NG2 progenitors produce fewer $\mathrm{APC}^{+}$cells compared with control transplants, and a larger proportion of transplanted NG2 progenitors express GFAP $14 \mathrm{~d}$ after transplantation. The data presented here suggests that BMP4 is a gliogenic cue in the PI stem cell niche that can be manipulated to direct progenitor differentiation. In conjunction, previous studies have also demonstrated that glial populations can be augmented by inhibiting noggin within the CNS, which indirectly upregulates BMP signaling without an effect on cell proliferation (Hampton et al., 2007). Alternately, the action of BMP4 could be to delay differentiation after transplantation since BMP signals have been demonstrated to regulate the "stemness" of adult progenitors and function to preserve an astrocyte stem cell (Alvarez-Buylla and Lim, 2004) and GFAP ${ }^{+}$progenitors are proposed to be more stem like (Ma et al., 2005). Whether sustained increases in BMP4 expression act to preserve the stemness of latent progenitors, or whether BMP4 promotes stemness (as indicated by increased $\mathrm{GFAP}^{+}$cells), BMP ligands could be administered to remodel the PI niche to direct recovery. Together, the coordinated instruction of proliferation and differentiation would act to promote the maintenance of stem cell populations and differentiation to reestablish a stem cell niche.

Using the combination of a viral NG2 reporter and transplanted NG2-expressing progenitor cells, we have shown that instructions within the PI niche change temporally to produce both expected and unique cell lineages from neural progenitors after a hemisection SCI. We focused this study on the hemisection because it does not have the wave of inflammation and demyelination that follows a contusion injury. Hence, it is easier to demarcate the border zones of the injury site. The effect on the niche or the mediators of the niche (e.g., blood, cell death, inflammation, etc.) would likely be similar at the lesion epicenter of a hemisection or a contusion. However, the secondary complications are more prolific after a contusion injury despite the cut meninges that coincide the laceration of a hemisection (Popovich and Hickey, 2001; Donnelly and Popovich, 2008). Therefore, a contusion injury is larger and has a widespread inflammatory response, which is a result of the mechanical trauma to the vascular system and shearing of axons over larger distances. Understanding the process and the mechanism by which progenitor fates are directed by PI niches will be important to develop therapeutic tools that are (1) at the mercy of the inherent cues within progressive niche, (2) designed to augment recovery from a posttraumatic injury through transplantation of exongenous stem cells, and (3) do not introduce acute injuries after intervention. Additionally, understanding how niche succession is coordinated will elucidate how endogenous and transplanted progenitors respond to injury and how best to therapeutically manage their participation in tissue regeneration.

\section{References}

Aguirre A, Dupree JL, Mangin JM, Gallo V (2007) A functional role for EGFR signaling in myelination and remyelination. Nat Neurosci 10:990-1002.

Ahn S, Joyner AL (2004) Dynamic changes in the response of cells to positive hedgehog signaling during mouse limb patterning. Cell 118:505-516.
Alonso G (2005) NG2 proteoglycan-expressing cells of the adult rat brain: possible involvement in the formation of glial scar astrocytes following stab wound. Glia 49:318-338.

Alvarez-Buylla A, Lim DA (2004) For the long run: maintaining germinal niches in the adult brain. Neuron 41:683-686.

Arnett HA, Fancy SP, Alberta JA, Zhao C, Plant SR, Kaing S, Raine CS, Rowitch DH, Franklin RJ, Stiles CD (2004) bHLH transcription factor Olig1 is required to repair demyelinated lesions in the CNS. Science 306:2111-2115.

Aschner M (1998) Astrocytic functions and physiological reactions to injury: the potential to induce and/or exacerbate neuronal dysfunction-a forum position paper. Neurotoxicology 19:7-17, discussion 37-18.

Belachew S, Chittajallu R, Aguirre AA, Yuan X, Kirby M, Anderson S, Gallo V (2003) Postnatal NG2 proteoglycan-expressing progenitor cells are intrinsically multipotent and generate functional neurons. J Cell Biol 161:169-186.

Boyes BE, Kim SU, Lee V, Sung SC (1986) Immunohistochemical colocalization of S-100b and the glial fibrillary acidic protein in rat brain. Neuroscience 17:857-865.

Brand AH, Perrimon N (1993) Targeted gene expression as a means of altering cell fates and generating dominant phenotypes. Development 118:401-415.

Buffo A, Rite I, Tripathi P, Lepier A, Colak D, Horn AP, Mori T, Gotz M (2008) Origin and progeny of reactive gliosis: a source of multipotent cells in the injured brain. Proc Natl Acad Sci U S A 105:3581-3586.

Cahoy JD, Emery B, Kaushal A, Foo LC, Zamanian JL, Christopherson KS, Xing Y, Lubischer JL, Krieg PA, Krupenko SA, Thompson WJ, Barres BA (2008) A transcriptome database for astrocytes, neurons, and oligodendrocytes: a new resource for understanding brain development and function. J Neurosci 28:264-278.

Cepko CL, Ryder E, Austin C, Golden J, Fields-Berry S, Lin J (1998) Lineage analysis using retroviral vectors. Methods 14:393-406.

Dawson MR, Polito A, Levine JM, Reynolds R (2003) NG2-expressing glial progenitor cells: an abundant and widespread population of cycling cells in the adult rat CNS. Mol Cell Neurosci 24:476-488.

Doetsch F, Caille I, Lim DA, Garcia-Verdugo JM, Alvarez-Buylla A (1999) Subventricular zone astrocytes are neural stem cells in the adult mammalian brain. Cell 97:703-716.

Donnelly DJ, Popovich PG (2008) Inflammation and its role in neuroprotection, axonal regeneration and functional recovery after spinal cord injury. Exp Neurol 209:378-388.

Eng LF, Ghirnikar RS (1994) GFAP and astrogliosis. Brain Pathol 4:229-237.

Fawcett JW, Asher RA (1999) The glial scar and central nervous system repair. Brain Res Bull 49:377-391.

Fuchs E, Tumbar T, Guasch G (2004) Socializing with the neighbors: stem cells and their niche. Cell 116:769-778.

Gibson BW, Gilliom RD, Whitaker JN, Biemann K (1984) Amino acid sequence of human myelin basic protein peptide $45-89$ as determined by mass spectrometry. J Biol Chem 259:5028-5031.

Golden JA, Fields-Berry SC, Cepko CL (1995) Construction and characterization of a highly complex retroviral library for lineage analysis. Proc Natl Acad Sci U S A 92:5704-5708.

Hampton DW, Rhodes KE, Zhao C, Franklin RJ, Fawcett JW (2004) The responses of oligodendrocyte precursor cells, astrocytes and microglia to a cortical stab injury, in the brain. Neuroscience 127:813-820.

Hampton DW, Asher RA, Kondo T, Steeves JD, Ramer MS, Fawcett JW (2007) A potential role for bone morphogenetic protein signalling in glial cell fate determination following adult central nervous system injury in vivo. Eur J Neurosci 26:3024-3035.

Horky LL, Galimi F, Gage FH, Horner PJ (2006) Fate of endogenous stem/ progenitor cells following spinal cord injury. J Comp Neurol 498:525-538.

Horner PJ, Power AE, Kempermann G, Kuhn HG, Palmer TD, Winkler J, Thal LJ, Gage FH (2000) Proliferation and differentiation of progenitor cells throughout the intact adult rat spinal cord. J Neurosci 20:2218-2228.

Horner PJ, Thallmair M, Gage FH (2002) Defining the NG2-expressing cell of the adult CNS. J Neurocytol 31:469-480.

Johansson CB, Momma S, Clarke DL, Risling M, Lendahl U, Frisen J (1999) Identification of a neural stem cell in the adult mammalian central nervous system. Cell 96:25-34.

Jordan JD, Ma DK, Ming GL, Song H (2007) Cellular niches for endogenous 
neural stem cells in the adult brain. CNS Neurol Discord Drug Targets 6:336-341.

Kahn MA, Ellison JA, Chang RP, Speight GJ, de Vellis J (1997) CNTF induces GFAP in a S-100 alpha brain cell population: the pattern of CNTFalpha $\mathrm{R}$ suggests an indirect mode of action. Brain Res Dev Brain Res 98:221-233.

Keirstead HS, Blakemore WF (1999) The role of oligodendrocytes and oligodendrocyte progenitors in CNS remyelination. Adv Exp Med Biol 468:183-197.

Keirstead HS, Levine JM, Blakemore WF (1998) Response of the oligodendrocyte progenitor cell population (defined by NG2 labelling) to demyelination of the adult spinal cord. Glia 22:161-170.

Kempermann G, Wiskott L, Gage FH (2004) Functional significance of adult neurogenesis. Curr Opin Neurobiol 14:186-191.

Kim SU, de Vellis J (2005) Microglia in health and disease. J Neurosci Res 81:302-313.

Levine JM, Nishiyama A (1996) The NG2 chondroitin sulfate proteoglycan: a multifunctional proteoglycan associated with immature cells. Perspect Dev Neurobiol 3:245-259.

Levine JM, Reynolds R (1999) Activation and proliferation of endogenous oligodendrocyte precursor cells during ethidium bromide-induced demyelination. Exp Neurol 160:333-347.

Lillien L, Raphael H (2000) BMP and FGF regulate the development of EGFresponsive neural progenitor cells. Development 127:4993-5005.

Lim DA, Tramontin AD, Trevejo JM, Herrera DG, Garcia-Verdugo JM, Alvarez-Buylla A (2000) Noggin antagonizes BMP signaling to create a niche for adult neurogenesis. Neuron 28:713-726.

Lytle JM, Wrathall JR (2007) Glial cell loss, proliferation and replacement in the contused murine spinal cord. Eur J Neurosci 25:1711-1724.

Ma DK, Ming GL, Song H (2005) Glial influences on neural stem cell development: cellular niches for adult neurogenesis. Curr Opin Neurobiol 15:514-520.

Ma M, Basso DM, Walters P, Stokes BT, Jakeman LB (2001) Behavioral and histological outcomes following graded spinal cord contusion injury in the C57Bl/6 mouse. Exp Neurol 169:239-254.

Martenson RE (1984) Myelin basic protein speciation. Prog Clin Biol Res 146:511-521.

McTigue DM, Wei P, Stokes BT (2001) Proliferation of NG2-positive cells and altered oligodendrocyte numbers in the contused rat spinal cord. J Neurosci 21:3392-3400.

Meletis K, Barnabe-Heider F, Carlen M, Evergren E, Tomilin N, Shupliakov O, Frisen J (2008) Spinal cord injury reveals multilineage differentiation of ependymal cells. PLoS Biol 6:e182.

Namiki J, Tator CH (1999) Cell proliferation and nestin expression in the ependyma of the adult rat spinal cord after injury. J Neuropathol Exp Neurol 58:489-498.

Ninkovic J, Götz M (2007) Signaling in adult neurogenesis: from stem cell niche to neuronal networks. Curr Opin Neurobiol 17:338-344.

Palmer TD (2002) Adult neurogenesis and the vascular Nietzsche. Neuron 34:856-858.

Polito A, Reynolds R (2005) NG2-expressing cells as oligodendrocyte progenitors in the normal and demyelinated adult central nervous system. J Anat 207:707-716.

Popovich PG, Hickey WF (2001) Bone marrow chimeric rats reveal the unique distribution of resident and recruited macrophages in the contused rat spinal cord. J Neuropathol Exp Neurol 60:676-685.

Ramirez-Castillejo C, Sanchez-Sanchez F, Andreu-Agullo C, Ferron SR,
Aroca-Aguilar JD, Sanchez P, Mira H, Escribano J, Farinas I (2006) Pigment epithelium-derived factor is a niche signal for neural stem cell renewal. Nat Neurosci 9:331-339.

Reier PJ, Houle JD (1988) The glial scar: its bearing on axonal elongation and transplantation approaches to CNS repair. Adv Neurol 47:87-138.

Ronnevi LO (1978) Origin of the glial processes responsible for the spontaneous postnatal phagocytosis of boutons on cat spinal motoneurons. Cell Tissue Res 189:203-217.

Samanta J, Kessler JA (2004) Interactions between ID and OLIG proteins mediate the inhibitory effects of BMP4 on oligodendroglial differentiation. Development 131:4131-4142.

Shen Q, Goderie SK, Jin L, Karanth N, Sun Y, Abramova N, Vincent P, Pumiglia K, Temple S (2004) Endothelial cells stimulate self-renewal and expand neurogenesis of neural stem cells. Science 304:1338-1340.

Shihabuddin LS, Horner PJ, Ray J, Gage FH (2000) Adult spinal cord stem cells generate neurons after transplantation in the adult dentate gyrus. J Neurosci 20:8727-8735.

Silver J, Miller JH (2004) Regeneration beyond the glial scar. Nat Rev Neurosci 5:146-156.

Smith GM, Miller RH, Silver J (1986) Changing role of forebrain astrocytes during development, regenerative failure, and induced regeneration upon transplantation. J Comp Neurol 251:23-43.

Song H, Stevens CF, Gage FH (2002) Astroglia induce neurogenesis from adult neural stem cells. Nature 417:39-44.

Song HJ, Stevens CF, Gage FH (2002) Neural stem cells from adult hippocampus develop essential properties of functional CNS neurons. Nat Neurosci 5:438-445.

Streit WJ (2000) Microglial response to brain injury: a brief synopsis. Toxicol Pathol 28:28-30.

Tzeng SF, Kahn M, Liva S, De Vellis J (1999) Tumor necrosis factor-alpha regulation of the Id gene family in astrocytes and microglia during CNS inflammatory injury. Glia 26:139-152.

Vives V, Alonso G, Solal AC, Joubert D, Legraverend C (2003) Visualization of S100B-positive neurons and glia in the central nervous system of EGFP transgenic mice. J Comp Neurol 457:404-419.

Wang X, Seed B (2003) A PCR primer bank for quantitative gene expression analysis. Nucleic Acids Res 31:e154.

Weiss S, Dunne C, Hewson J, Wohl C, Wheatley M, Peterson AC, Reynolds BA (1996) Multipotent CNS stem cells are present in the adult mammalian spinal cord and ventricular neuroaxis. J Neurosci 16:7599-7609.

Westley B, Rochefort H (1980) A secreted glycoprotein induced by estrogen in human breast cancer cell lines. Cell 20:353-362.

Wu D, Shibuya S, Miyamoto O, Itano T, Yamamoto T (2005) Increase of NG2-positive cells associated with radial glia following traumatic spinal cord injury in adult rats. J Neurocytol 34:459-469.

Yanagisawa M, Takizawa T, Ochiai W, Uemura A, Nakashima K, Taga T (2001) Fate alteration of neuroepithelial cells from neurogenesis to astrocytogenesis by bone morphogenetic proteins. Neurosci Res 41:391-396.

Ying QL, Nichols J, Chambers I, Smith A (2003) BMP induction of Id proteins suppresses differentiation and sustains embryonic stem cell selfrenewal in collaboration with STAT3. Cell 115:281-292.

Zai LJ, Wrathall JR (2005) Cell proliferation and replacement following contusive spinal cord injury. Glia 50:247-257.

Zhu X, Bergles DE, Nishiyama A (2008) NG2 cells generate both oligodendrocytes and gray matter astrocytes. Development 135:145-157. 